Portland State University

PDXScholar

\title{
Projections of Large-Scale Atmospheric Circulation Patterns and Associated Temperature and Precipitation Over the Pacific Northwest Using CMIP6 Models
}

Graham Patrick Taylor

Portland State University

Follow this and additional works at: https://pdxscholar.library.pdx.edu/open_access_etds

Part of the Climate Commons, and the Geography Commons Let us know how access to this document benefits you.

\section{Recommended Citation}

Taylor, Graham Patrick, "Projections of Large-Scale Atmospheric Circulation Patterns and Associated Temperature and Precipitation Over the Pacific Northwest Using CMIP6 Models" (2021). Dissertations and Theses. Paper 5776.

https://doi.org/10.15760/etd.7647

This Thesis is brought to you for free and open access. It has been accepted for inclusion in Dissertations and Theses by an authorized administrator of PDXScholar. Please contact us if we can make this document more accessible: pdxscholar@pdx.edu. 
Projections of Large-Scale Atmospheric Circulation Patterns and Associated

Temperature and Precipitation over the Pacific Northwest Using CMIP6 Models

by

Graham Patrick Taylor

A thesis submitted in partial fulfillment of the requirements for the degree of

\author{
Master of Science \\ in \\ Geography
}

\title{
Thesis Committee: \\ Paul Loikith, Chair \\ Heejun Chang \\ Andrew Martin
}

Portland State University

2021 
(C) 2021 Graham Patrick Taylor 


\begin{abstract}
Projections of $500 \mathrm{hPa}$ geopotential height (Z500) patterns over the Pacific Northwest of North America and their associated surface temperature, precipitation, and frequency of occurrence are assessed using models from the 6th phase of the Coupled Model Intercomparison Project (CMIP6). The self-organizing maps approach is applied to reanalysis data from the Modern-Era Retrospective Analysis for Research and Applications, version-2 (MERRA-2) to cluster daily Z500 anomalies into 12 representative patterns that span the range of historical circulation patterns. CMIP6 data for daily Z500 anomalies are mapped to each node for historical and end of century global warming experiments, and the resulting differences in Z500 anomaly patterns, their associated temperature and precipitation, and pattern frequency occurrence are analyzed. Models project a reduction in the amplitude of Z500 anomalies, with majority model agreement on significant reduction found in JJA and SON. The largest temperature increases in DJF are found for patterns historically associated with anomalously cold weather, while the largest temperature increases in JJA are found in patterns historically associated with anomalously warm weather. Precipitation is found to generally increase across all seasons and patterns, however some historically wet JJA patterns become significantly drier. Significant changes in pattern frequencies are found across seasons, with a general decrease in frequency of highly amplified Z500 anomaly patterns compared to the recent historical climate.
\end{abstract}




\section{Table of Contents}

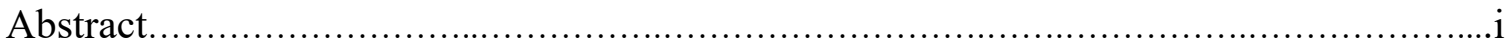

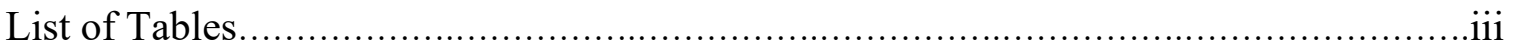

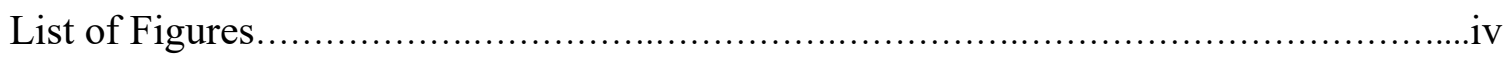

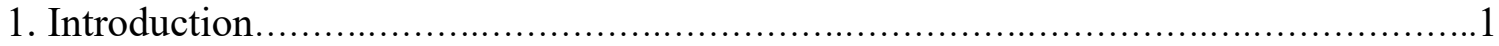

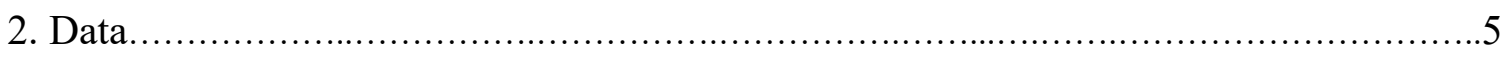

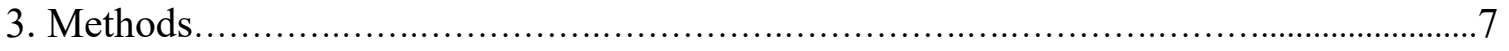

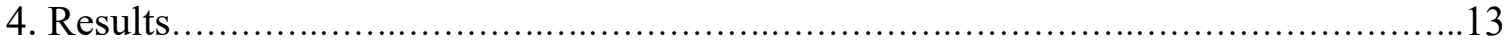

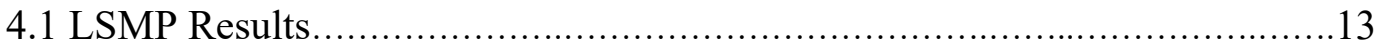

4.1.1 DJF Pattern Results..................................................14

4.1.2 DJF Frequency Results.................................................17

4.1.3 MAM Pattern Results....................................................19

4.1.4 MAM Frequency Results.................................................21

4.1.5 JJA Pattern Results.....................................................23

4.1.6 JJA Frequency Results...........................................25

4.1.7 SON Pattern Results................................................27

4.1.7 SON Frequency Results ............................................29

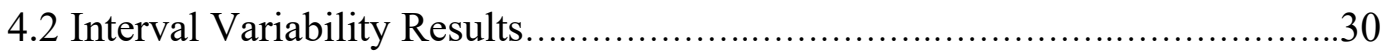

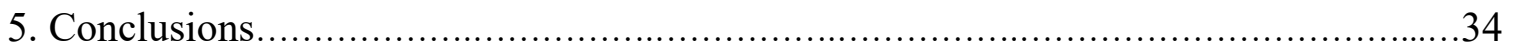

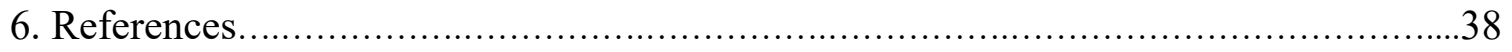




\section{List of Tables}

Table 1 CMIP6 models and their native resolutions. Variables used are Z500, T2M, PR.

Models with * are not available for PR...........................................6 


\section{List of Figures}

Figure 1. DJF results for a. Historical (1985:2014) Z500 anomaly LSMPs created by the model-SOM method. Solid contours are anomalies, black as negative and white as positive. Color fill is total Z500. Node headings indicate node numbers, which will be used in the same order for subsequent plots. b. 2071:2100 change in anomalies compared to historical. Shading indicates end of century change, contours are end of century anomalies with white as positive and black as negative, spaced at $3 \mathrm{~m}$. c. Change in temperature $\left({ }^{\circ} \mathrm{C}\right)$. Contours are historical anomalies, solid as positive and dashed as negative, spaced at $1^{\circ}$. d. Change in precipitation as percentage, contours are historical anomalies spaced at $25 \%$. Stippling shows where at least half of the 16 models project statistically significant change of the same sign at the $95 \%$ confidence interval according

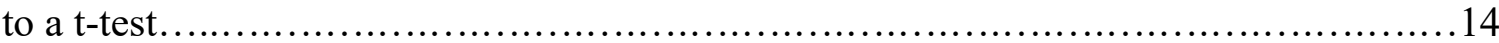

Figure 2. DJF LSMP frequency trends. a. Colors indicate the number of models agreeing on statistically significance increase in frequency (orange), decrease in frequency (blue), or no change in frequency (gray). Numbers indicate historical MMEM LSMP frequency, defined by percentage of days over a 30 year time period assigned to that node. b. Time series of individual model frequency per node. MMEM in blue. Average trend numbers indicate whether the MMEM trend shows significant increase (1) decrease (-1) or no

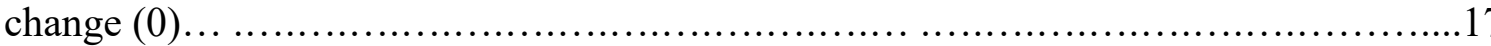

Figure 3. MMEM MAM Results. a. Historical LSMPs. Solid contours are anomalies, black as negative and white as positive. Color fill is total Z500. Node headings indicate node numbers, which will be used in the same order for subsequent node plots. $\mathbf{b}$. 2071:2100 change in anomalies compared to historical. Shading indicates end of century change, contours are end of century anomalies with white as positive and black as negative, spaced at $3 \mathrm{~m}$. c. Change in temperature $\left({ }^{\circ} \mathrm{C}\right)$. Contours are historical anomalies, solid as positive and dashed as negative, spaced at $1^{\circ}$. All models at all grid cells show statistically significant change so stippling is not applied here. $\mathbf{d}$. Change in precipitation as percentage, contours are historical anomalies spaced at $25 \%$. Stippling shows where at least half of the models project statistically significant change of the same sign at the $95 \%$ confidence interval according to a t-test

Figure 4. MAM LSMP frequency trends. a. Colors indicate the number of models agreeing on statistically significance increase in frequency (orange), decrease in frequency (blue), or no change in frequency (gray). Numbers indicate historical MMEM LSMP frequency, defined by percentage of days over a 30 year time period assigned to that node. b. Time series of individual model frequency per node. MMEM in blue. Average trend numbers indicate whether the MMEM trend shows significant increase (1)

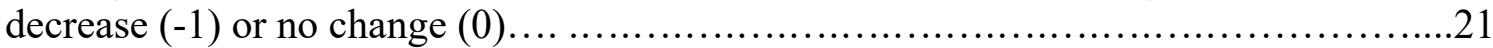


Figure 5. MMEM JJA Results. a. Historical LSMPs. Solid contours are anomalies, black as negative and white as positive. Color fill is total Z500. Node headings indicate node numbers, which will be used in the same order for subsequent node plots. b. 2071:2100 change in anomalies compared to historical. Shading indicates end of century change, contours are end of century anomalies with white as positive and black as negative, spaced at $3 \mathrm{~m}$. Stippling shows where at least half of the models project statistically significant change of the same sign at the $95 \%$ confidence interval according to a t-test. c. Change in temperature $\left({ }^{\circ} \mathrm{C}\right)$. Contours are historical anomalies, solid as positive and dashed as negative, spaced at $1^{\circ}$. All models at all grid cells show statistically significant change so stippling is not applied here. $\mathbf{d}$. Change in precipitation as percentage, contours are historical anomalies spaced at 25\%. White stippling shows where at least half of the models project statistically significant change of the same sign at the $95 \%$ confidence

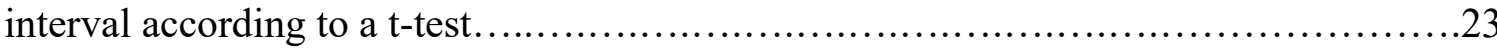

Figure 6. JJA LSMP frequency trends. a. Colors indicate the number of models agreeing on statistically significance increase in frequency (orange), decrease in frequency (blue), or no change in frequency (gray). Numbers indicate historical MMEM LSMP frequency, defined by percentage of days over a 30 year time period assigned to that node. b. Time series of individual model frequency per node. MMEM in blue. Average trend numbers indicate whether the MMEM trend shows significant increase (1) decrease (-1) or no

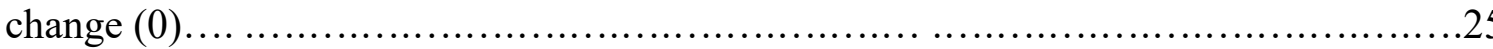

Figure 7. MMEM SON Results. a. Historical LSMPs. Solid contours are anomalies, black as negative and white as positive. Color fill is total Z500. Node headings indicate node numbers, which will be used in the same order for subsequent node plots. $\mathbf{b}$. 2071:2100 change in anomalies compared to historical. Shading indicates end of century change, contours are end of century anomalies with white as positive and black as negative, spaced at $3 \mathrm{~m}$. Stippling shows where at least half of the models project statistically significant change of the same sign at the $95 \%$ confidence interval according to a t-test. c. Change in temperature $\left({ }^{\circ} \mathrm{C}\right)$. Contours are historical anomalies, solid as positive and dashed as negative, spaced at $1^{\circ}$. All models at all grid cells show statistically significant change so stippling is not applied here. d. Change in precipitation as percentage, contours are historical anomalies spaced at $25 \%$. Red stippling shows where at least half of the models project statistically significant change of the same sign

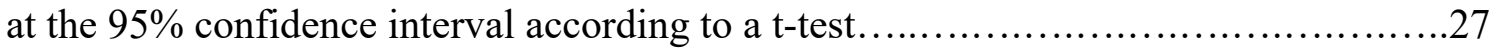

Figure 8. SON LSMP frequency trends. a. Colors indicate the number of models agreeing on statistically significance increase in frequency (orange), decrease in frequency (blue), or no change in frequency (gray). Numbers indicate historical MMEM LSMP frequency, defined by percentage of days over a 30 year time period assigned to that node. b. Time series of individual model frequency per node. MMEM in blue. 
Average trend numbers indicate whether the MMEM trend shows significant increase (1)

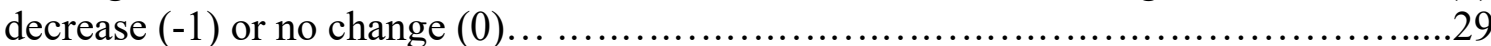

Figure 9. JJA internal variability results for change in anomalies and node frequency. a. Individual variant end of century change in Z500 anomaly results correlated with ensemble average, by node, for CanESM5. b. Time series of individual variant node frequency change, with variant ensemble average in purple, for CanESM5. c. As in panel a, for MPI-ESM1-2-LR. d. As in panel b, for MPI-ESM1-2-LR ........................30

Figure 10. SON internal variability results for change in anomalies and node frequency. a. Individual variant end of century change in Z500 anomaly results correlated with ensemble average, by node, for CanESM5. b. Time series of individual variant node frequency change, with variant ensemble average in purple, for CanESM5. c. As in panel $a$, for MPI-ESM1-2-LR. d. As in panel $b$, for MPI-ESM1-2-LR ........................32 


\section{Introduction}

The climate of the Pacific Northwest exhibits considerable seasonality, with distinct wet and dry seasons, and significant influence from topography and the adjacent Pacific Ocean. The wet season is crucial for replenishing water resources, and variability in wet season precipitation can create water resource challenges, whereas summer typically consists of meteorological drought and can feature heatwaves. Drier than average spring conditions or a reduction in the frequency of storm patterns can lead to strains on water supplies, and winter storm-producing circulation patterns can cause extensive flooding and damage (Mahoney et al., 2018). Changes in circulation patterns would therefore have a large effect on weather and its impacts on the Pacific Northwest. This study assesses changes in those large scale patterns in global warming scenarios.

Extreme mid-latitude weather is often linked to synoptic scale circulation and features (Horton et al., 2015). Negative anomalies in Z500 over the Pacific have been associated with cool season extreme precipitation events in the region (Lackman \& Gyakum, 1999; Warner et al., 2012), whereas positive Z500 anomalies have been linked to heat waves (Meehl \& Tebaldi, 2004). Salathé (2006) found that wet season storm tracks in the Pacific Northwest are influenced by the Aleutian Low, and that climate change may shift the position of both to the north. Atmospheric rivers and troughs can be linked to extreme precipitation and flooding in the Pacific Northwest (Radić et al., 2015; Schlef et al., 2019), and anomalously long lasting ridges can contribute to drought (Liu et al., 2018; Teng \& Branstator, 2017) and extreme heat (Horton et al., 2016). CMIP5 models have been found to project a weakening of mid-tropospheric geopotential height gradients in the Pacific Northwest summer (Brewer \& Mass, 2016), and there have been 
numerous studies on potential changes to landfalling atmospheric rivers on the West Coast (Dettinger, 2011; Gao et al., 2015; Hagos et al., 2016; Warner et al., 2015). Analyzing whether projections show changes in the intensity or persistence of synoptic circulation patterns over the Pacific Northwest in CMIP6 models may contribute to regional resilience, the ability to prepare for and react to hazardous events, and resource management. However, few studies have performed a systematic assessment of projections of large scale circulation patterns over the Pacific Northwest, motivating this study.

There is a challenge in predicting long term changes to weather in the Pacific Northwest due to the fact that weather in the region is frequently associated with the interaction of atmospheric phenomena and local topography, and global climate models often cannot capture that interaction. This is because the grid resolution of most global climate models is larger than the scale at which weather patterns interact with local topography (Wilby \& Wigley, 1997), an issue which is minimized when analyzing large scale circulation patterns. Therefore, an approach that analyzes the large scale drivers of weather can be used to analyze projections. Previous studies have used this method to study weather in the Pacific Northwest, including Warner et al. (2012), which used synoptic scale climatology to study extreme precipitation, and Loikith et al. (2017), which characterized the large scale meteorological patterns (LSMPs) in the Pacific Northwest and linked them to extreme precipitation and temperature. Aragon et al. (2020) characterized the LSMPs that are associated with heavy rainfall over Portland, Oregon. Large scale circulation features have been connected to local scale extreme precipitation in other regions of the Continental United States as well (Agel et al., 2018; Collow et al., 
2016; Gao et al., 2014). LSMPs have also been used to study extreme temperature events (Grotjahn et al., 2016; Grotjahn \& Faure, 2008; Loikith \& Broccoli, 2012), and climate model skill at simulating LSMPs has been assessed in a number of studies (Cassano et al., 2006; Gibson et al., 2016; Grotjahn, 2013; Loikith \& Broccoli, 2015). By connecting large scale circulation with local weather, we can assess how climate change might alter the frequency or character of local weather impacts by analyzing how climate change may shift the frequency or character of those large scale patterns. Model simulations of LSMPs have been used to evaluate climate change in numerous regions, including Australia (Gibson et al., 2017), New Zealand (Gibson et al., 2016), Alaska (Glisan et al., 2016), Greenland (Belleflame et al., 2013), and the larger Arctic region (Cassano et al., 2006).

Impactful weather in the mid-latitudes is often driven by Rossby Waves, and potential changes in the amplitude of those waves would significantly impact the occurrence of extreme events (Röthlisberger et al., 2016). Under global warming, the Arctic is warming at a faster rate than lower latitudes, a phenomenon termed arctic amplification (Cohen et al., 2014), and researchers have found links between the increased arctic warming and extreme or changing mid-latitude weather patterns (Cohen et al., 2014; Francis \& Vavrus, 2012), through possible changes in storm tracks, the jet stream, or Rossby waves.

However, there is not yet a consensus on the effects of arctic warming on mid-latitude weather, motivating further study on the effect of climate change on circulation patterns and mid-latitude weather.

There is additional uncertainty around the projections of change in precipitation in the Pacific Northwest due to global warming. The $4^{\text {th }}$ national climate assessment (Wuebbles 
et al., 2017) found that end of century projections for change in precipitation over the region are not significantly greater than natural climate variability. Abatzoglou et al. (2014) found that CMIP5 models had poor skill at producing and projecting seasonal precipitation in the Pacific Northwest, suggesting that additional methods may be needed to understand climate projections over the region. Mote \& Salathé (2010) used CMIP3 models to evaluate the climate of the Pacific Northwest in the 2080s and found that while projected changes in annual precipitation are small, some models show increased fall and winter precipitation and decreased summer precipitation.

This study seeks to analyze how atmospheric circulation patterns over the Pacific Northwest are projected to change due to global warming by the end of the $21^{\text {st }}$ century. In this research, atmospheric circulation patterns refer to patterns of $500 \mathrm{hPa}$ geopotential height anomalies, a variable that can be related to the zonal and meridional flow of air in the mid-troposphere. Because geopotential height can be analyzed on a large spatial scale, its behavior is independent of local topography and analysis of its projections in climate models will minimize the complex topography issues detailed above. Using this method, we seek to determine whether the character of atmospheric circulation patterns over the Pacific Northwest is projected to change due to global warming, whether certain circulation patterns are projected to become more or less frequent, and how temperature and precipitation associated with characteristic circulation patterns are projected to change. 


\section{Data}

Daily reference data for 500-hPa geopotential height (Z500) are from the ModernEra Retrospective analysis for Research and Applications, Version 2 (MERRA2; Gelaro et al., 2017), which is provided on a global $0.5^{\circ}$ by $0.625^{\circ}$ latitude/longitude grid.

Climate model data for Z500, 2-meter temperature (T2M), and precipitation flux (PR) are from a set of 16 models (Table 1) contributing to the sixth phase of the Coupled Model Intercomparison Project, (CMIP6; Eyring et al., 2016). Due to limited data availability at the time this analysis was undertaken, PR is analyzed for 11 models. All data are regridded to a $2^{\circ}$ latitude/longitude grid. Reanalysis data and historical CMIP6 data are assessed using a 30-year time period covering 1985-2014. Future CMIP6 data use the ssp585 emissions scenario, which assumes high-end emissions going forward in the $21^{\text {st }}$ century. This scenario is chosen to maximize the anthropogenic climate forcing signal for optimal detection of change. For the primary analysis, only one ensemble member from each model is employed (rli1p1f1). An assessment investigating the contribution from internal variability is also performed using 10 ensemble members from two models (CanESM5, MPI-ESM1-2-LR), each with different initial condition realizations. 


\begin{tabular}{ll}
\hline Model & Native Resolution (Lat x Long) \\
\hline ACCESS-CM2 & $1.25^{\circ} \times 1.88^{\circ}$ \\
BCC-CSM2-MR* & $1.12^{\circ} \times 1.13^{\circ}$ \\
CESM2-WACCM & $0.94^{\circ} \times 1.25^{\circ}$ \\
CESM2 & $0.94^{\circ} \times 1.25^{\circ}$ \\
CanESM5* & $2.79^{\circ} \times 2.81^{\circ}$ \\
EC-Earth3* & $0.7^{\circ} \times 0.7^{\circ}$ \\
GFDL-CM4 & $2^{\circ} \times 2.5^{\circ}$ \\
INM-CM4-8* & $1.5^{\circ} \times 2^{\circ}$ \\
INM-CM5-0 & $1.5^{\circ} \times 2^{\circ}$ \\
IPSL-CM6A-LR & $1.27^{\circ} \times 2.5^{\circ}$ \\
MIROC6 & $1.4^{\circ} \times 1.41^{\circ}$ \\
MPI-ESM1-2-HR & $0.94^{\circ} \times 0.94^{\circ}$ \\
MPI-ESM1-2-LR* & $1.87^{\circ} \times 1.88^{\circ}$ \\
MRI-ESM2-0 & $1.12^{\circ} \times 1.13^{\circ}$ \\
NorESM2-LM & $1.89^{\circ} \times 2.5^{\circ}$ \\
NorESM2-MM & $0.94^{\circ} \times 1.25^{\circ}$
\end{tabular}

Table 1: CMIP6 models and their native resolutions. Variables used are Z500, T2M, PR. Models with * are not available for PR. 


\section{Methods}

We define LSMPs as key meteorological variables that drive weather over large spatial scales, as in Loikith et al. (2017). In this case, we use $500 \mathrm{hPa}$ geopotential height anomalies as the primary variable to define the LSMPs. Geopotential height at $500 \mathrm{hPa}$, approximately halfway between the surface of the earth and the tropopause, is a variable that can be used diagnostically to infer the horizontal and vertical movement of air, processes that are a significant factor in analyzing weather on a synoptic scale.

The self-organizing map (SOM) approach is used to characterize LSMPs, defined as anomalies in Z500 over the Pacific Northwest for each three-month meteorological season (December, January, February (DJF); March, April, May (MAM); June, July, August (JJA); September, October, November (SON)). SOMs are a type of unsupervised neural network used to cluster data into a chosen number of output nodes (Hewitson \& Crane, 2002). SOMs have been used in synoptic climatology in numerous studies, and have been validated as a useful technique. Hewiston \& Crane (2002) summarized their application to synoptic climatology, and other studies have used the technique to characterize LSMPs over the Pacific Northwest (Aragon et al., 2020; Loikith et al., 2017), to analyze projected changes in patterns according to climate models over a number of regions (Belleflame et al., 2013; Gibson et al., 2016; Gibson et al., 2017; Sinha et al., 2018), and to analyze a range of atmospheric phenomena (Glisan et al., 2016; Johnson et al., 2008; Johnson \& Feldstein, 2010; Lennard \& Hegerl, 2015; Mechem et al., 2018). The SOM approach has also been used to study synoptic weather patterns in climate models (Cassano et al., 2006; Loikith \& Broccoli, 2015), and to connect LSMPs with temperature and precipitation extremes (Cassano et al., 2015; Cavazos, 2000; Ford 
\& Schoof, 2017; Gibson et al., 2017; Loikith et al., 2017; Loikith \& Broccoli, 2015). The SOM method produces a set of LSMPs in a specific order, in which node adjacency between each LSMP is proportional to how similar the patterns are. The SOM approach is chosen over other clustering techniques, such as k-means, because the method produces a continuum of results, reflective of the continuous nature of atmospheric circulation patterns.

Z500 anomalies are provided as the SOM input instead of total field to reduce the influence of the seasonal cycle, especially in the transition seasons. The SOM algorithm creates a data space over the input data set, with a user-chosen number of nodes initially spaced evenly throughout. The number of nodes is determined by the researcher, and for this study 12 nodes were chosen. There is a balance between capturing the full range of patterns using a large number of nodes, and producing interpretable results by using a smaller number of nodes. Choosing the correct number of nodes for the relevant application will ideally result in a full characterization of regional climatology, with high interpretability and limited pattern repetition. Through experimentation with a range of node configurations, we determined the use of 12 nodes to be sufficient for capturing the key features of Pacific Northwest seasonal climatology while remaining interpretable in each season. The use of 12 nodes to characterize the Pacific Northwest has been used in previous studies, including Loikith et al. (2017) and Aragon et al. (2020).

The SOM algorithm produces a set of 12 LSMPs that span the range of synoptic patterns for each meteorological season. Data are confined to an area over the Pacific Northwest bounded by $36^{\circ} \mathrm{N}$ and $60^{\circ} \mathrm{N}$ latitude, and $114^{\circ} \mathrm{W}$ and $146^{\circ} \mathrm{W}$ longitude. We first construct a 12-node "reference-SOM" using daily MERRA2 Z500 anomalies, which 
are computed by removing the 7-day average 30-year climatology (1985-2014), centered on each day, from each day, as input to the SOM algorithm for each season. We chose an output structure of a $3 \times 4$ sheet rectangular grid, an approach used to characterize Pacific Northwest climatology by Loikith et al. (2017). The user must also choose two neighborhood parameters, which determine the magnitude of node adjustment in each step of the SOM algorithm. We chose an initially large neighborhood radius $(r=4)$ to ensure the SOM nodes successfully map the input data using 2000 iterations, and a secondary smaller neighborhood radius $(r=1)$ to stabilize the fine adjustment using 2000 iterations, both using a gaussian neighborhood function.

In the first step of the SOM algorithm, the first input data point, which is a daily data point of Z500 anomaly from MERRA-2, is selected. The Euclidean distance between the input data point and all 12 nodes in the data space is measured, and the node with the smallest Euclidean distance is chosen as the "winning" node. This "winning" node is then moved towards the input data point, and adjacent nodes are shifted as well, proportional to the neighborhood parameter. This routine is repeated for every input data point, over 2000 iterations, until every input data point has shifted the node placement. This process is repeated with a smaller neighborhood parameter to make fine adjustments and converge in a final configuration, thus "self organizing" the nodes into a $3 \mathrm{x} 4$ node grid of Z500 anomaly patterns that have been trained on historical climate (reference-SOM), and can be considered representative of the range of possible LSMPs over the Pacific Northwest for the input time period.

In order to analyze future changes in the SOM patterns, climate model simulations of reanalysis Z500 anomaly patterns must be created, in order to compare 
historical LSMPs in climate models to future LSMPs in the same models. Thus, we use a similar approach to map climate models to the reference-SOM. We measure the Euclidean distance between each Z500 anomaly day in a climate model time series and all 12 reference-SOM nodes, and the node with the smallest Euclidean distance is chosen as the "winning" node. The model day is then assigned to that "winning" node. This process is repeated for every day in the model time series, until each day is assigned to a reference-SOM node. The Z500 anomaly data assigned to each node is then averaged, to create a 3 x 4 node grid of LSMPs (model-SOM). Ensemble mean model-SOMs are created by averaging individual model results. A similar method of mapping model data to a reference-SOM has been used to study projections of mean sea level pressure related to Australian heatwaves in Gibson et al. (2017). A quantitative evaluation of models' ability to accurately represent reanalysis patterns was undertaken, and it was found that models are able to accurately simulate the key elements of atmospheric circulation over the region.

This approach is repeated for future 30-year time periods to create projected future model-SOMs. T2M and PR composites are created by averaging their respective data associated with each Z500 anomaly day assigned to each node to create modelSOMs of T2M and PR that correspond with Z500 anomaly LSMPs. This is done for historical and end of century time periods, and the change in model ensemble mean T2M and PR associated with the Z500 anomaly LSMPs is evaluated. The difference between the multi-model ensemble (MMEM) of end of century LSMPs and the historical LSMPs (2071:2100 - 1985:2014) is evaluated for change by subtracting the historical modelSOM LSMPs from the future model-SOM LSMPs. 
Trends in LSMP frequency are computed using the following procedure. First, a model-SOM is constructed for the 30-year period of 1985-2014. Then, the frequency of occurrence of each node during that 30 -year period, defined by percentage of days assigned to that node, is counted and assigned to the first trend time step. This process is then repeated for the next 30-year period advanced by one year (1986-2015, 1987-2016, and so on) until 2071-2100. This results in a timeseries of node occurrence consisting of 85 timesteps for each node. A Mann-Kendall test is applied to assess trend significance at the $95 \%$ confidence interval. These steps are repeated for each of the 16 models, and a node is considered to have a significant trend if at least half of the 16 models exhibit a significant trend of the same sign.

To assess whether results are influenced by simulation initial conditions, we repeat the above analysis for two models (CanESM5 and MPI-ESM1-2-LR) each with 10 ensemble members consisting of different initial conditions. This analysis is performed to identify the degree to which internal variability affects future projections of circulation patterns versus external forcing. We note that this is not a comprehensive assessment of the effect of internal variability because we are only using two models with only 10 ensembles. However, results provide additional information on the robustness of the multi-model results. We assess results for correlation with average variant change patterns on a node by node basis, comparing results from individual realization variants (as in figure 1b) to the variant ensemble mean future change results for that model. Model realization variants refer to the conditions at which the model is initialized. If there is a high correlation between different variants and the ensemble mean, initial conditions are considered to be less likely as the main signal contributing to end-of-century results. 
Similarly, node frequency analysis is repeated for 10 variants from 2 models and evaluated for significant change by end-of-century. Majority agreement of variants on sign and significance of node frequency change is interpreted as evidence against initial conditions being the dominant signal influencing results. 


\section{Results}

\subsection{LSMP Results}

Results are analyzed by meteorological season using five main criteria: the structure of LSMPs in model-SOMs, the end of century change of LSMPs in modelSOMs, the end of century change in temperature associated with LSMPs, the end of century change in precipitation associated with LSMPs, and the change in frequency of LSMP occurrence. Maps of projected change, excluding temperature, use stippling to indicate at which grid cells at least half of the 16 models (eight or more) exhibit a statistically significant change at the $95 \%$ confidence interval of the same sign (positive or negative) using a t-test. Stippling is not used in temperature change maps because all grid cells meet the stippling criteria. 


\subsubsection{DJF Pattern Results}

a.
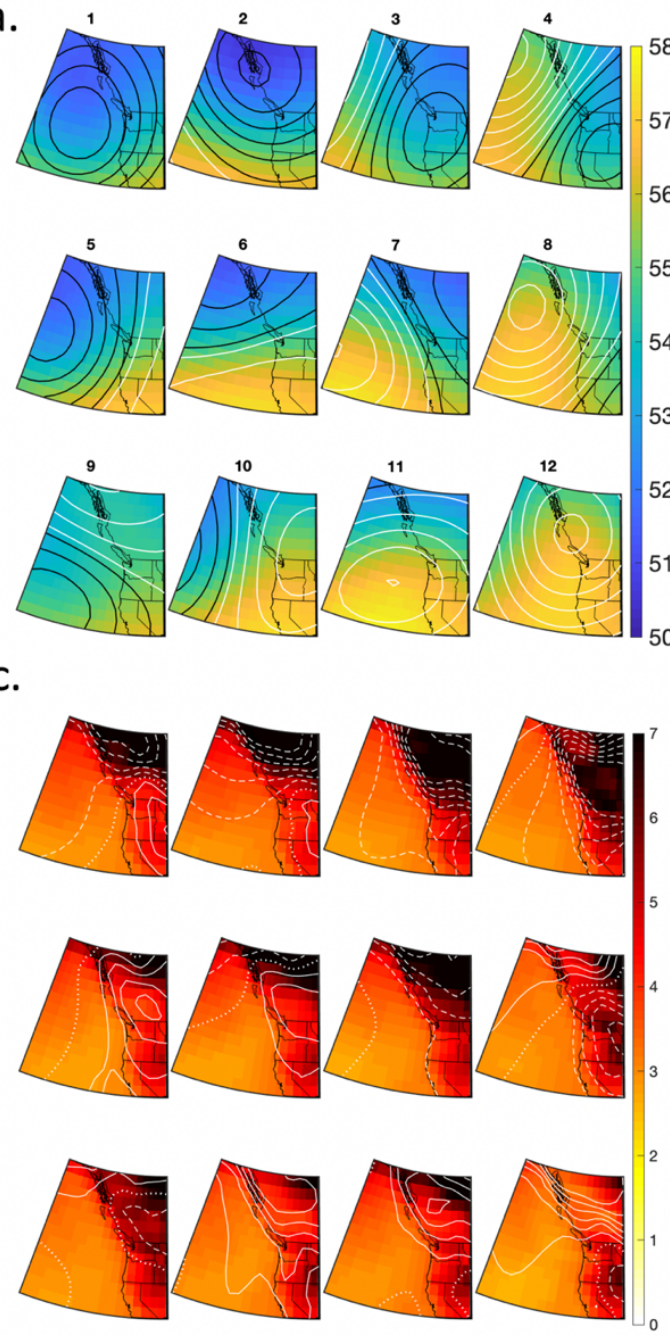

b.

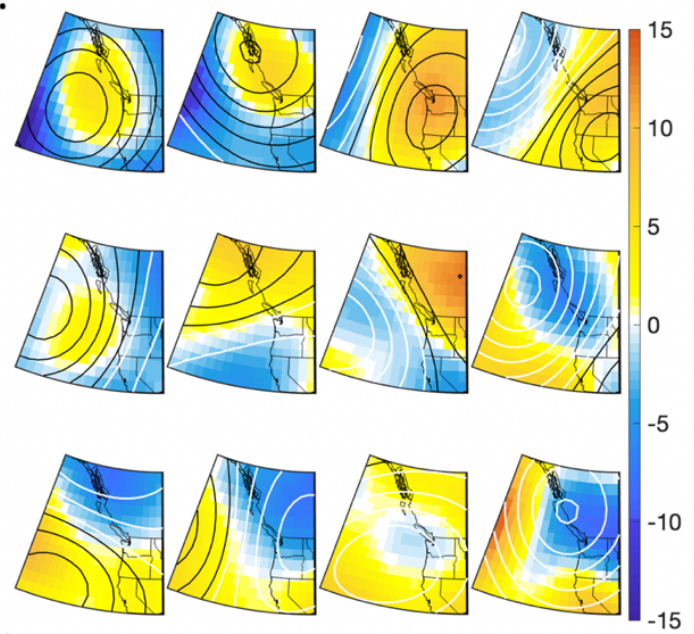

d.

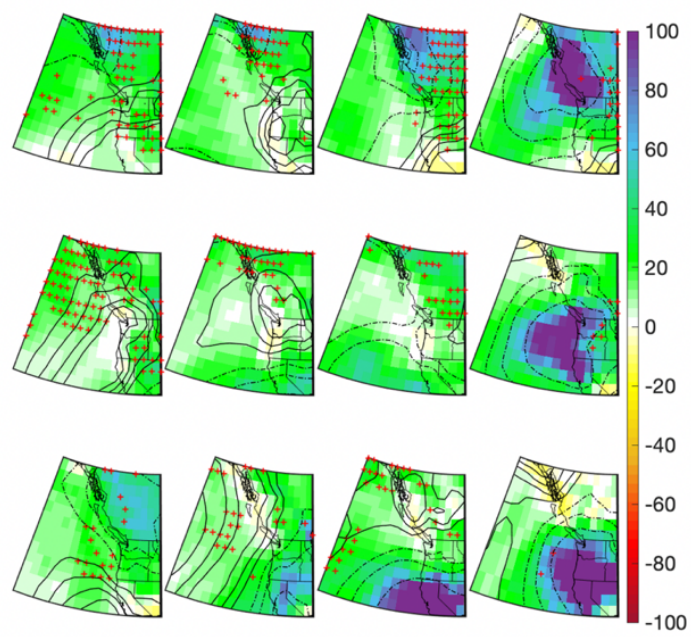

Figure 1. DJF results for a. Historical (1985:2014) Z500 anomaly LSMPs created by the model-SOM method. Solid contours are anomalies, black as negative and white as positive. Color fill is total Z500. Node headings indicate node numbers, which will be used in the same order for subsequent plots. $\mathbf{b}$. 2071:2100 change in anomalies compared to historical. Shading indicates end of century change, contours are end of century anomalies with white as positive and black as negative, spaced at $3 \mathrm{~m}$. c. Change in temperature $\left({ }^{\circ} \mathrm{C}\right)$. Contours are historical anomalies, solid as positive and dashed as negative, spaced at $1^{\circ}$. d. Change in precipitation as percentage, contours are historical anomalies spaced at $25 \%$. Stippling shows where at least half of the 16 models project statistically significant change of the same sign at the $95 \%$ confidence interval according to a t-test.

Figure 1 shows results for the 12 LSMPs defined by the SOM approach for DJF.

Node numbers will be used throughout the analysis, in the same order as shown in panel 
(a). Figure 1a shows the model-SOM, providing the reference period range of LSMPs, with Z500 anomalies contoured (the quantity used in the SOM construction) and the composite of Z500 total field values for all days assigned to each node shaded. In general, the top left nodes of the SOM matrix are defined by negative Z500 anomaly patterns over the Pacific Northwest, while the bottom right nodes are defined by positive Z500 anomaly patterns over the region, with the intermediate nodes encompassing zonal flow patterns and weaker ridges and troughs. For example, node 1 shows a strong negative anomaly centered over the Pacific, west of the Oregon and Washington coasts, corresponding to an upstream trough. Node 12 shows a strong positive anomaly centered over the British Columbia coast, corresponding to a ridge over the region.

Figure $1 \mathrm{~b}$ shows the end of century change in anomaly patterns, plotted as color fill, with end of century anomaly patterns as contours. The anomaly patterns are found to not change appreciably, but a general trend of reduction in anomaly magnitude is observed. For example, node 1 shows a positive change relative to the reference period, indicating a reduction of the magnitude of the negative anomalies. Similar weakening of negative anomalies can be observed in node 2 , node 3 , and node 7 . Conversely, a weakening of positive anomalies is observed in nodes with a historically strong positive anomaly pattern. This can be seen most clearly in node 8 , node 11 , and node 12 . However, at no grid points do at least half of the models exhibit a statistically significant change of the same sign.

Figure 1c shows the end of century change in average T2M associated with each node, and the historical multi-model mean temperature anomaly contoured in white. All grid cells meet the significance criteria of at least half of the 16 models showing a 
statistically significant warming and therefore no stippling is applied. All nodes exhibit a high degree of warming, with more warming over land and less warming over the ocean. The greatest warming is found in nodes $1-4$, and node 7 . As indicated by the dashed contours, these are nodes that have historically been anomalously cold in interior continental areas. Nodes 3 and 4 in particular have historically been the coldest, corresponding with negative anomaly patterns over the continent, and a deep trough facilitating the transport of arctic air to the interior. The relatively high degree of warming of these nodes may be attributed to the amplified warming of the arctic, the source region for the coldest air in the region (Screen, 2014). Historically warm patterns over the Pacific Northwest, node 5 and node 10, while showing a high degree of warming, do not exhibit the same level of warming as the historically cold patterns.

Figure 1d shows the end of century change in average daily precipitation, as a percentage change from historical, associated with each node. All nodes show some degree of increased precipitation overall. Node 4, node 8, node 11, and node 12 all show a large percentage change in precipitation, corresponding with areas that are historically dry, which would lead to a relatively small absolute increase in precipitation. These patterns all correspond to upstream ridges, often indicative of dry weather in the region. Historically wet patterns over the Pacific Northwest, notably node 2, node 5, and node 6, which all exhibit a zonal flow pattern at $500 \mathrm{hPa}$, show little to no change in precipitation. Agreement by more than half of the models on statistical significance varies spatially and across nodes, with the most notable agreement on increased precipitation over British Columbia in node 1, node 2, node 3, node 5, node 6, node 7, node 9 , and node 10. No nodes show a significant decrease in precipitation. This 
significant increase in precipitation to the north with a high degree of model agreement is consistent with existing projections of mean precipitation in winter (Huang \& Ullrich, 2017; Rupp et al., 2017).

\subsubsection{DJF Frequency Results}

a.

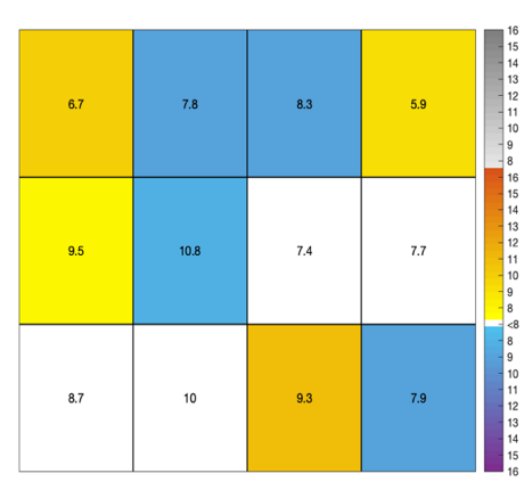

b.

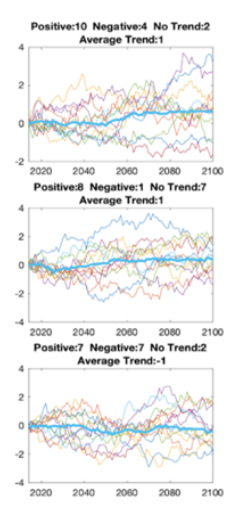

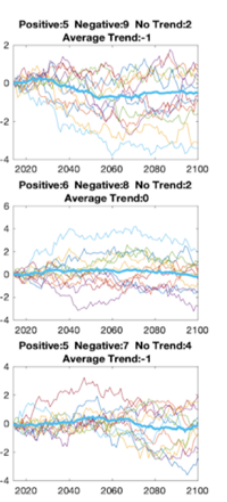
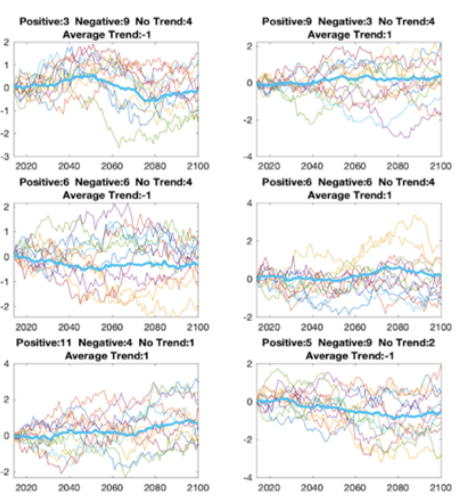

Figure 2. DJF LSMP frequency trends. a. Colors indicate the number of models agreeing on statistically significance increase in frequency (orange), decrease in frequency (blue), or no change in frequency (gray). Numbers indicate historical MMEM LSMP frequency, defined by percentage of days over a 30 year time period assigned to that node. $\mathbf{b}$. Time series of individual model frequency per node. MMEM in blue. Average trend numbers indicate whether the MMEM trend shows significant increase (1) decrease (-1) or no change (0).

Node trend results for each node for DJF are presented in Figure 2. The majority of models agree on a significant decrease in frequency of days assigned to node 2 , node 3 , node 6 , and node 12 . Node 2 , node 3 , and node 6 are negative anomaly patterns with the negative anomaly centered over the Pacific coast, while node 12 is a highly amplified positive anomaly pattern centered over Vancouver Island. Node 1, node 4, node 5, and node 11 show majority model agreement on significance increase in node frequency. The most common historical pattern, node 6 , a roughly zonal flow pattern, shows model 
agreement on significant decrease. The least common historical pattern, node 4 , a highly amplified trough and ridge pattern responsible for anomalously cold conditions (figure 1c), shows model agreement on significant increase. Less than half of models agreed on significance and sign of change for node 7 , node 7 , node 9 , and node 10. 


\subsubsection{MAM Pattern Results}

a.

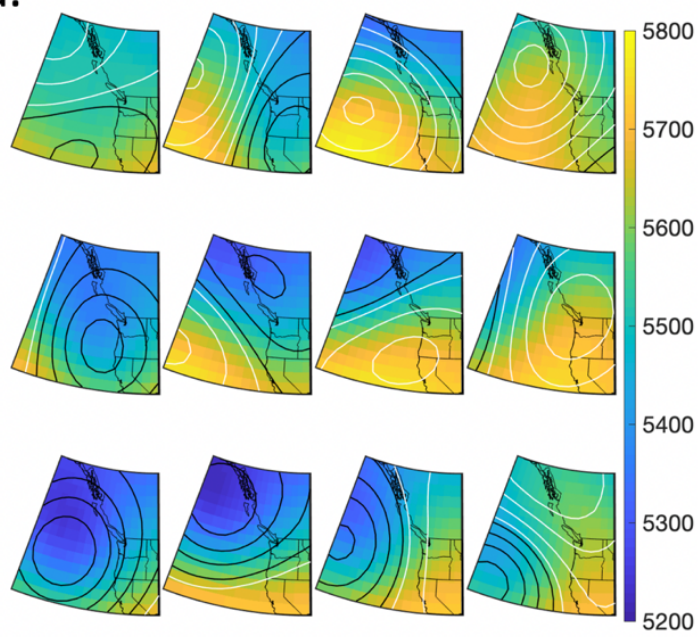

C.

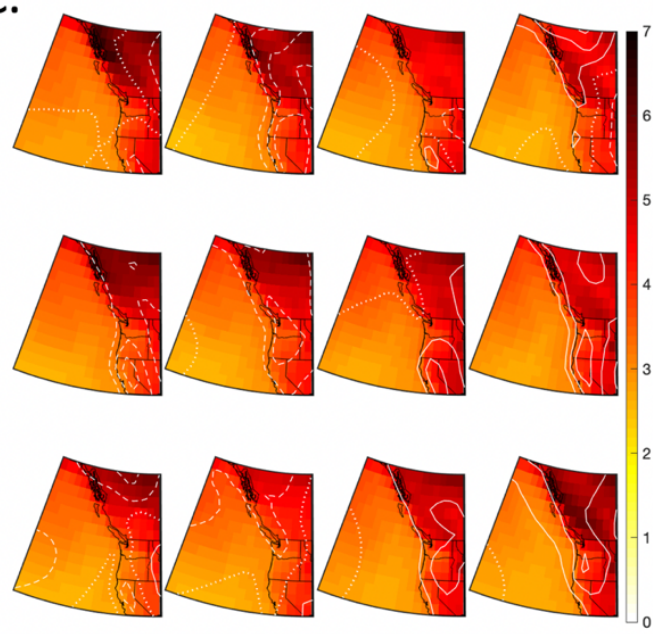

b.

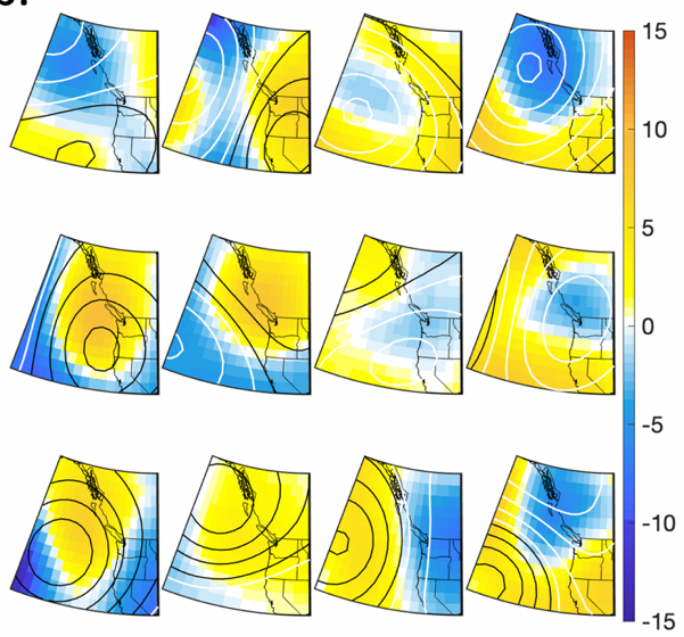

d.
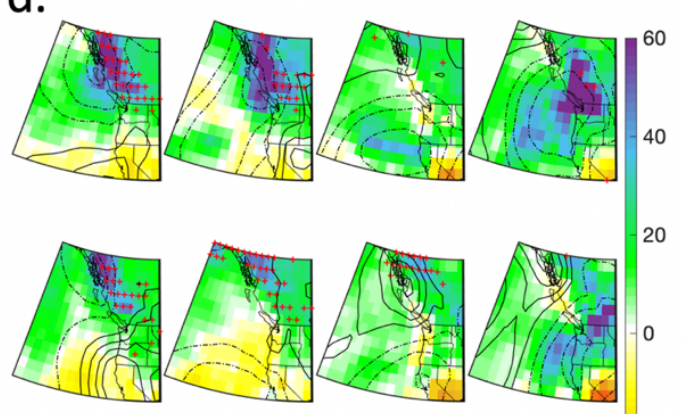

$-20$

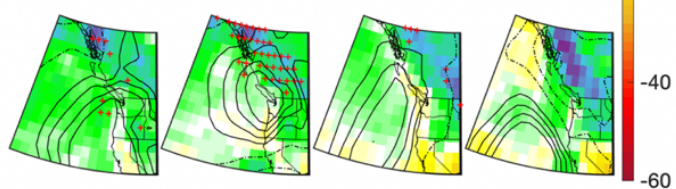

Figure 3. MMEM MAM Results. a. Historical LSMPs. Solid contours are anomalies, black as negative and white as positive. Color fill is total Z500. Node headings indicate node numbers, which will be used in the same order for subsequent node plots. b. 2071:2100 change in anomalies compared to historical. Shading indicates end of century change, contours are end of century anomalies with white as positive and black as negative, spaced at $3 \mathrm{~m}$. c. Change in temperature $\left({ }^{\circ} \mathrm{C}\right)$. Contours are historical anomalies, solid as positive and dashed as negative, spaced at $1^{\circ}$. All models at all grid cells show statistically significant change so stippling is not applied here. d. Change in precipitation as percentage, contours are historical anomalies spaced at 25\%. Stippling shows where at least half of the models project statistically significant change of the same sign at the $95 \%$ confidence interval according to a t-test. 
Results for MAM are shown in Figure 3. The lower left corner of the SOM (Figure 3a) tends towards negative anomalies over the Pacific, corresponding to upstream troughs, while the upper right corner exhibits positive anomalies over the Pacific, corresponding with typically drier weather (Figure 3d). Similar to DJF, end of century change in anomaly patterns shown in figure $3 \mathrm{~b}$ are found to generally exhibit a reduction in amplitude of anomaly patterns. Patterns with historically positive anomalies (node 4, node 8 ) show a decrease in anomaly height, while patterns with historically negative anomalies (node 5, node 9, node 10, node 11) show an increase in anomaly height. However, like DJF, at no grid point do at least half of the models exhibit a statistically significant change of the same sign, suggesting that these changes are not robust across the multi-model suite.

Figure $3 \mathrm{c}$ shows end of century temperature change. Compared to DJF results, the spatial relationship between historically anomalous temperature patterns and end of century temperature change is weaker, although the pattern of stronger inland warming than oceanic warming is maintained. The highest magnitude of warming is observed in node 1 , node 2 , and node 12, along the British Columbia coast range.

Figure $3 \mathrm{~d}$ shows end of century precipitation change as a percentage of historical precipitation. Large increases in precipitation are observed over the British Columbia coast in node 1 , node 2 , and node 5 , and large increases, as a percentage, over Northern Washington are observed in node 4 , all of which are notably patterns historically paired with anomalously dry conditions. More than half of the models agree on significant change and sign of change of precipitation in many areas, with strong agreement over the British Columbia coastal mountains. Drying trends are generally observed in most nodes 
over California, but at no grid points do at least half of the models agree on significance and sign of change. It is noted that in historically dry patterns, small absolute increases in precipitation will result on large percentage increases.

\subsubsection{MAM Frequency Results}

a.

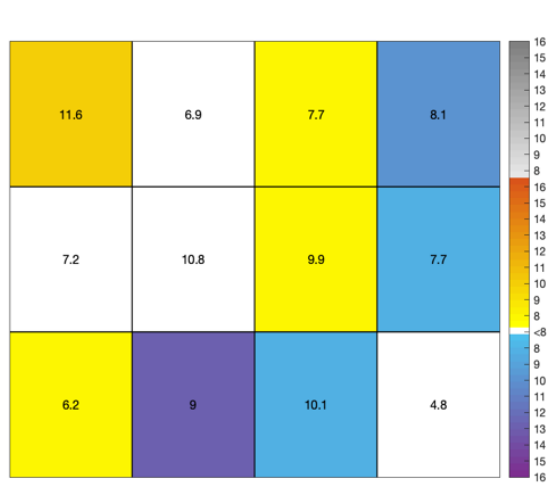

b.

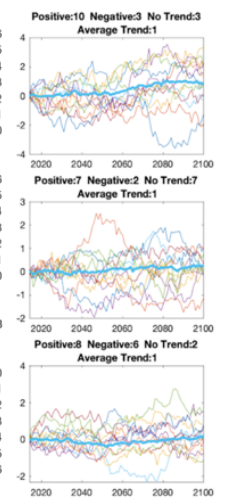

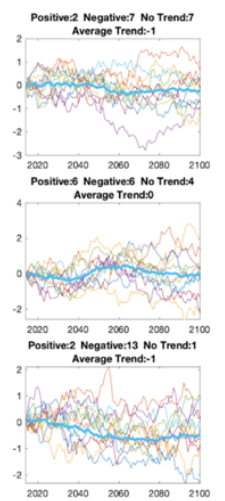

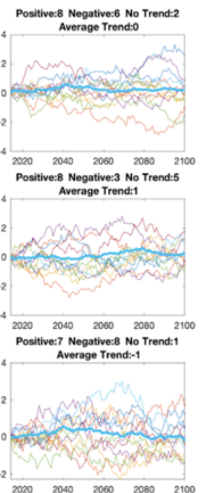

Figure 4. MAM LSMP frequency trends. a. Colors indicate the number of models agreeing on statistically significance increase in frequency (orange), decrease in frequency (blue), or no change in frequency (gray). Numbers indicate historical MMEM LSMP frequency, defined by percentage of days over a 30 year time period assigned to that node. $\mathbf{b}$. Time series of individual model frequency per node. MMEM in blue. Average trend numbers indicate whether the MMEM trend shows significant increase (1) decrease (-1) or no change (0).

Figure 4 shows model agreement on end of century LSMP frequency change for MAM. Node 1, node 3, node 7, and node 9 show model agreement on increasing node frequency. Apart from node 9, which is a strong negative anomaly, each of the nodes showing agreement on increasing frequency is a weaker anomaly pattern corresponding with zonal flow. Node 4 , node 8 , node 10 , and node 11 show decreasing frequency trends. Node 4 and node 8 are positive anomalies corresponding to an upstream ridge and a ridge over continent, respectively, while node 10 and node 11 are negative anomalies 
over the Pacific. Node 4 and node 10, which both show model agreement on significant decrease, are highly amplified patterns. Node 4 is a strong positive anomaly and corresponding ridge over the north Pacific, while node 10 is a strong negative anomaly over the north Pacific, corresponding to a steep low to high geopotential height gradient from north to south and indicative of strong zonal flow. Less than half of models agree on significance and sign of change for node 2 , node 5 , node 6 , and node 12 . 


\subsubsection{JJA Pattern Results}

a.

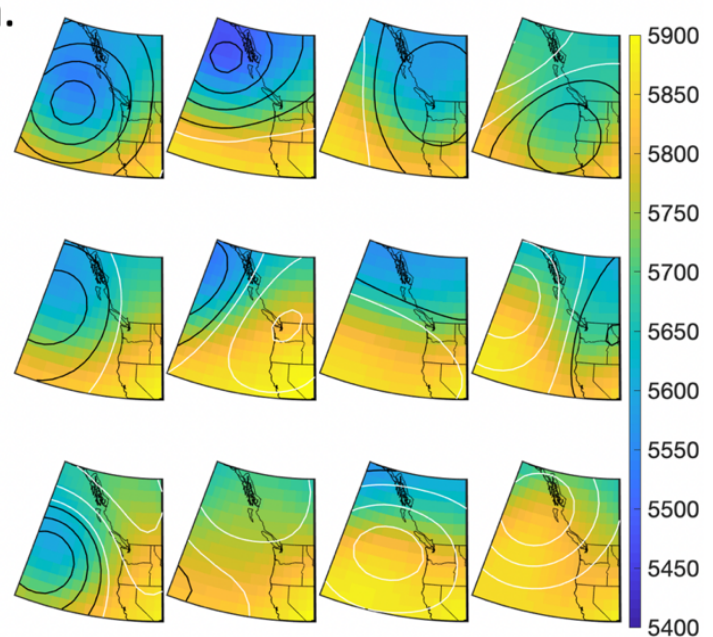

C.
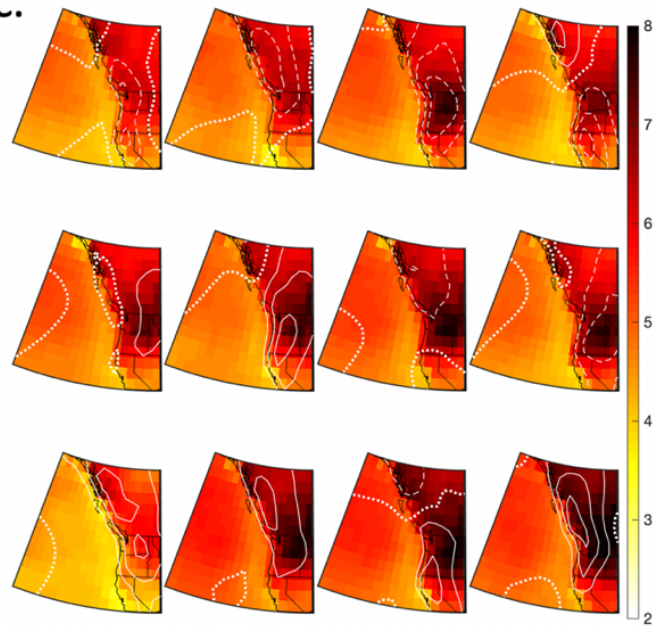

b.
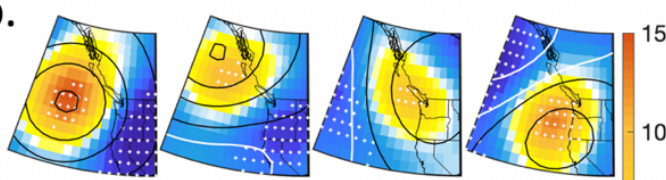

10
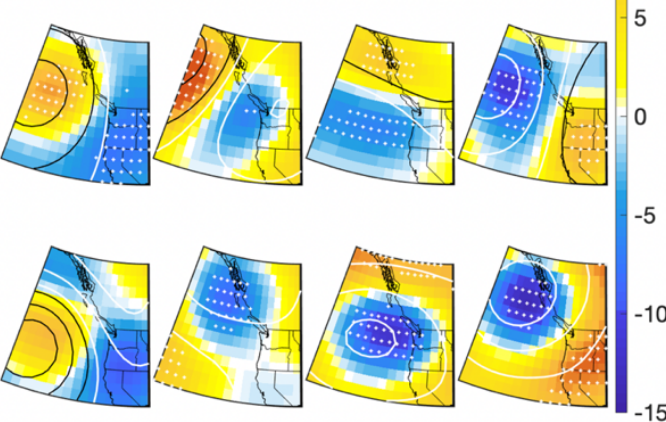

d.

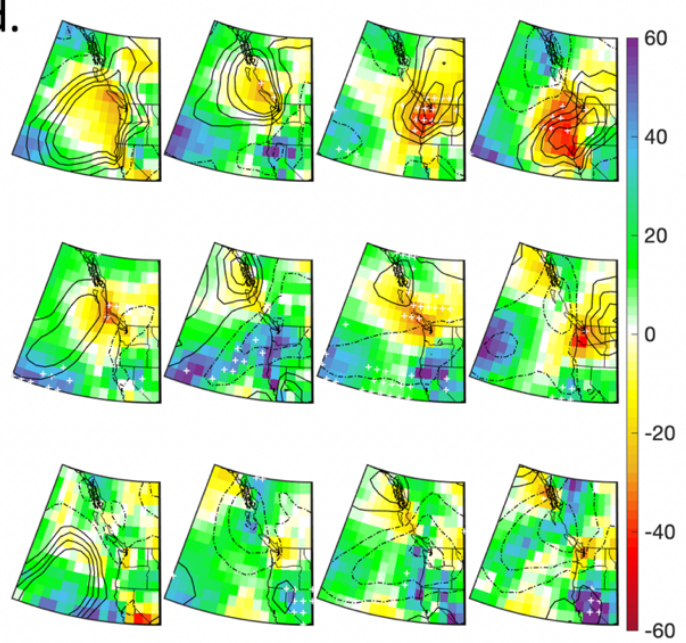

Figure 5. MMEM JJA Results. a. Historical LSMPs. Solid contours are anomalies, black as negative and white as positive. Color fill is total Z500. Node headings indicate node numbers, which will be used in the same order for subsequent node plots. b. 2071:2100 change in anomalies compared to historical. Shading indicates end of century change, contours are end of century anomalies with white as positive and black as negative, spaced at $3 \mathrm{~m}$. Stippling shows where at least half of the models project statistically significant change of the same sign at the $95 \%$ confidence interval according to a t-test. c. Change in temperature $\left({ }^{\circ} \mathrm{C}\right)$. Contours are historical anomalies, solid as positive and dashed as negative, spaced at $1^{\circ}$. All models at all grid cells show statistically significant change so stippling is not applied here. $\mathbf{d}$. Change in precipitation as percentage, contours are historical anomalies spaced at $25 \%$. White stippling shows where at least half of the models project statistically significant change of the same sign at the $95 \%$ confidence interval according to a t-test.

Results for JJA can be seen in Figure 5. Anomaly amplitudes are generally smaller than DJF and MAM, as geopotential height variability is lower in the warm 
season than the cold season due to a weaker meridional temperature gradient. End of century changes in anomaly patterns for JJA are shown in figure $5 \mathrm{~b}$. Results show a systematic decrease in anomaly amplitude across nodes, with positive anomalies decreasing in height (as in node 8 , node 10 , node 11 , and node 12 ), and negative anomalies increasing in height (as in node 1 , node 2 , node 4 , node 5 , node 7 , and node 8 ). Grid points where at least half of the models exhibit a statistically significant change of the same sign are shown in stippling, with most nodes showing some agreement centered on the strongest reduction in anomaly amplitudes, suggesting a robust signal across the multi-model suite.

Figure $5 \mathrm{c}$ shows temperature change, with historical anomalies contoured. A high level of warming is seen across nodes, with more warming inland. Some of the highest levels of warming can be seen in node 10 , node 11 , and node 12 , patterns which are historically the warmest. Those nodes correspond to positive anomalies and upstream ridges over the Pacific Northwest. Node 3, a negative anomaly associated with historically anomalous cold, also shows a high level of warming. The maximum warming is observed in eastern Oregon, Washington, Idaho, and interior British Columbia. All models agree on statistical significance.

Figure $5 \mathrm{~d}$ shows change in precipitation as a percentage. In this analysis, JJA is the only meteorological season to exhibit large areas of drying by end of the $21^{\text {st }}$ century, notably in node 3 and node 4 . Node 3 and node 4, which are historically the patterns responsible for summertime rainfall in the Pacific Northwest, show majority model agreement on statistically significant drying over Western Oregon and Washington. This result is interesting when observed together with temperature results, showing that the 
synoptic pattern associated with summertime rainfall and cool weather in the Pacific

Northwest (node 3) is projected to become significantly warmer and drier, as a

percentage. Unique among JJA precipitation results, node 12 shows majority model

agreement on a considerable increase in precipitation as a percentage over northern

California. It is worth noting that summer is climatologically dry across the region, thus

small absolute changes in precipitation equate to large percentage reductions.

\subsubsection{JJA Frequency Results}

a.

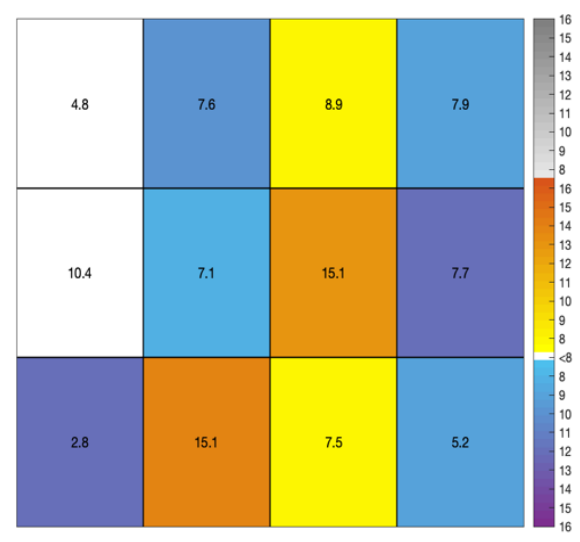

b.

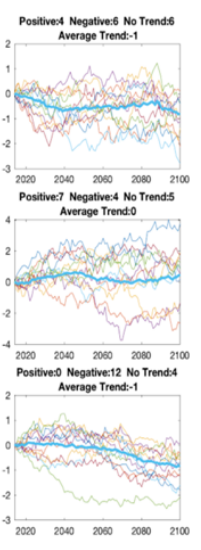

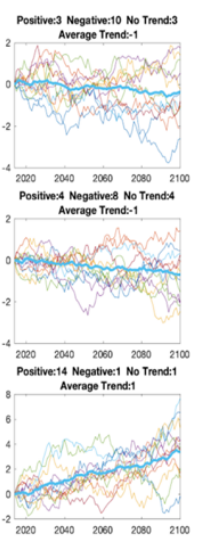
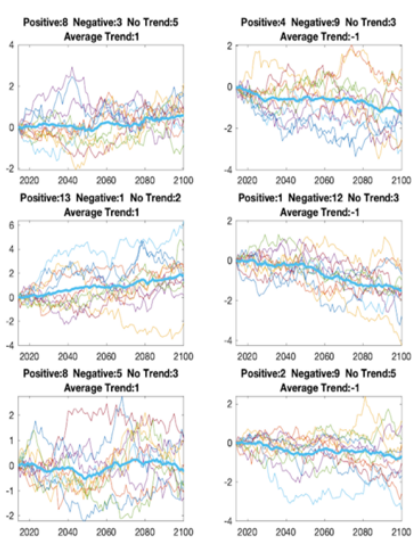

Figure 6. JJA LSMP frequency trends. a. Colors indicate the number of models agreeing on statistically significance increase in frequency (orange), decrease in frequency (blue), or no change in frequency (gray). Numbers indicate historical MMEM LSMP frequency, defined by percentage of days over a 30 year time period assigned to that node. $\mathbf{b}$. Time series of individual model frequency per node. MMEM in blue. Average trend numbers indicate whether the MMEM trend shows significant increase (1) decrease (-1) or no change (0).

LSMP frequency changes for JJA can be seen in figure 6. Models agree on an increase in frequency for node 3 , node 7 , node 10 , and node 11 . Node 7 , node 10 , and node 11 are relatively weak positive anomaly patterns showing zonal flow over the region, whereas node 3 is a negative anomaly trough centered over northern Washington. 
All other nodes apart from node 1 and node 5 show model agreement on decreasing frequency, with strong agreement on decreasing frequency for node 8 and node 9 , two relatively amplified ridge and trough patterns. Notably, JJA patterns in the Pacific Northwest are less evenly distributed as a percentage of days compared to other seasons. Nearly one third of historical JJA days are represented by node 7 and node 10, nodes with relatively weak anomalies and height gradients, and both nodes show strong model agreement on significant increases. Conversely, the relatively rare node 9 pattern of a strong negative anomaly offshore shows model agreement on significant decrease. 


\subsubsection{SON Pattern Results}

a.

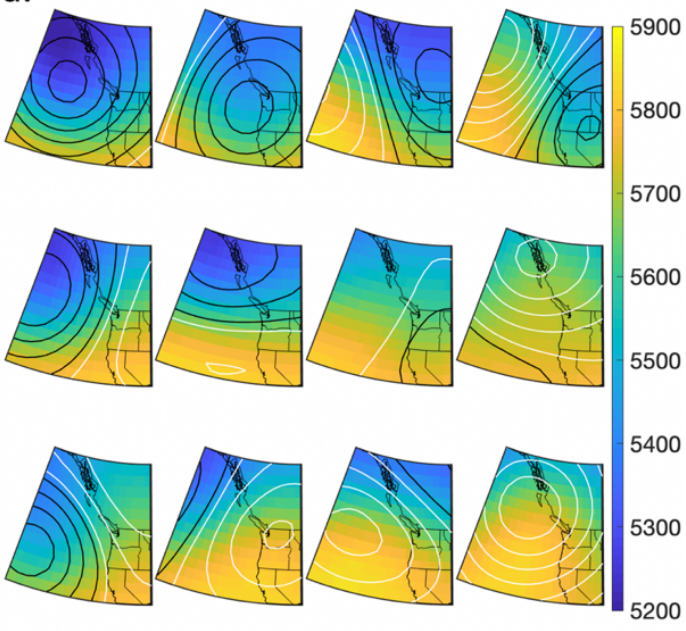

c.

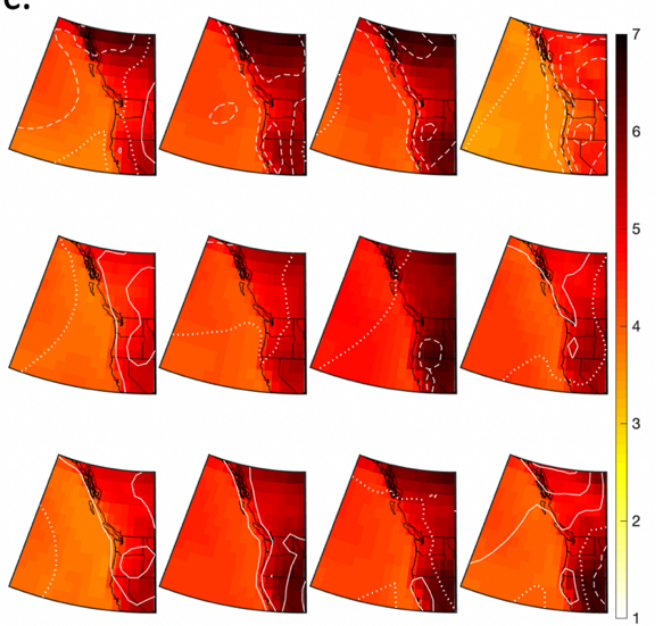

b.
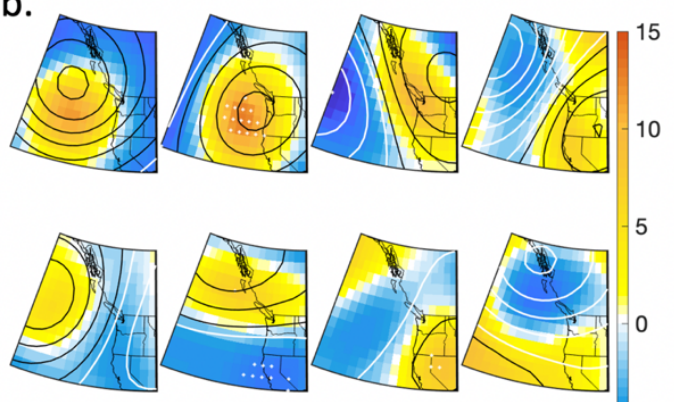

$-5$

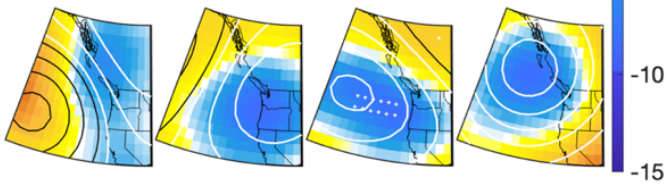

d.
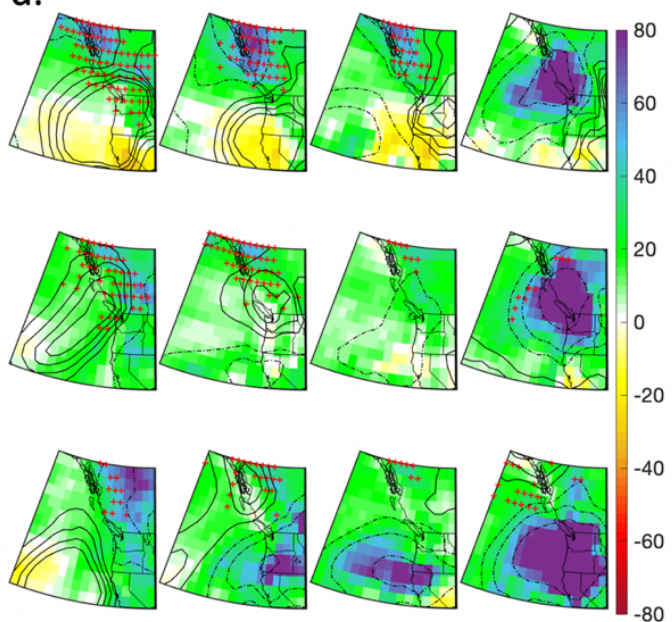

Figure 7. MMEM SON Results. a. Historical LSMPs. Solid contours are anomalies, black as negative and white as positive. Color fill is total Z500. Node headings indicate node numbers, which will be used in the same order for subsequent node plots. b. 2071:2100 change in anomalies compared to historical. Shading indicates end of century change, contours are end of century anomalies with white as positive and black as negative, spaced at $3 \mathrm{~m}$. Stippling shows where at least half of the models project statistically significant change of the same sign at the $95 \%$ confidence interval according to a t-test. c. Change in temperature $\left({ }^{\circ} \mathrm{C}\right)$. Contours are historical anomalies, solid as positive and dashed as negative, spaced at $1^{\circ}$. All models at all grid cells show statistically significant change so stippling is not applied here. d. Change in precipitation as percentage, contours are historical anomalies spaced at $25 \%$. Red stippling shows where at least half of the models project statistically significant change of the same sign at the $95 \%$ confidence interval according to a t-test. 
Results for SON are shown in Figure 7. Similar to JJA, a systematic reduction in anomaly amplitudes is found across nodes (Figure 7b), most apparent in nodes with historically high amplitude anomalies, such as node 1 , node 2 , node 8 , node 10 , node 11 , and node 12 . However, results with grid points where at least half of the models exhibit a statistically significant change of the same sign are confined to node 2 , node 6 , node 7 , and node 11 .

Similar to the MAM temperature analysis, temperature change for SON (Figure 7c) is more spatially homogeneous than DJF and JJA. All nodes show a high degree of warming, with largest magnitude of warming shown in inland areas including eastern California, Nevada, and southern Idaho, generally associated with positive anomalies and upstream ridge patterns. Node 2 and node 3, patterns historically associated with anomalously cold temperatures in interior Canada, also exhibit a large magnitude of warming.

Precipitation change for SON (Figure 7d) is generally found to increase in each pattern, apart from a drying trend observed in California and southern Oregon in node 1, node 2 , and node 3 . Large percentage increases in precipitation are observed in node 4, node 8 , and node 12 , patterns historically associated with dry weather, but model agreement on significance is less than half of the ensemble. More than half significance agreement on increasing rainfall is broadly confined to British Columbia in node 2, node 3 , node 5 , node 6 , and node 9 , while node 1 has significance agreement on increasing rainfall stretching from Alaska to eastern Oregon. In no grid cells did more than half of the models agree on significance and sign of change for precipitation south of Oregon. 


\subsubsection{SON Frequency Results}

a.

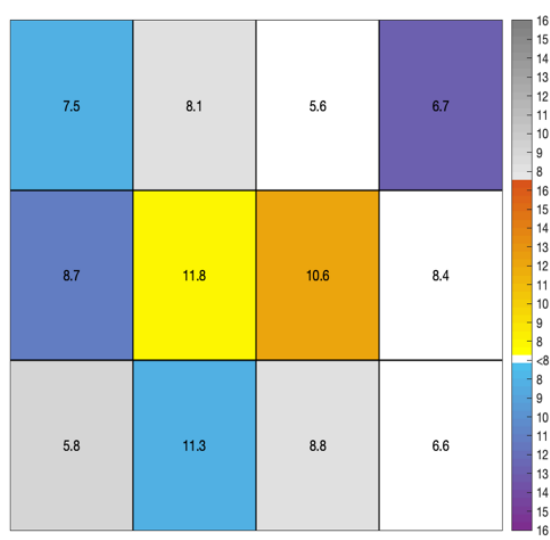

b.

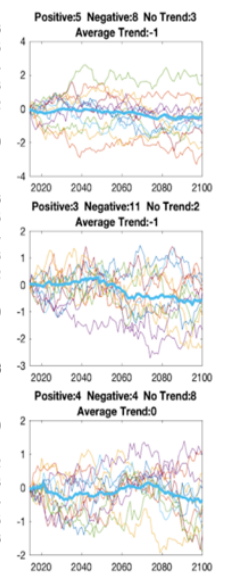

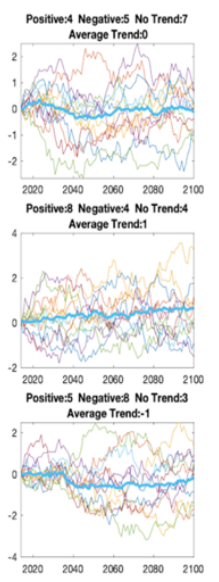

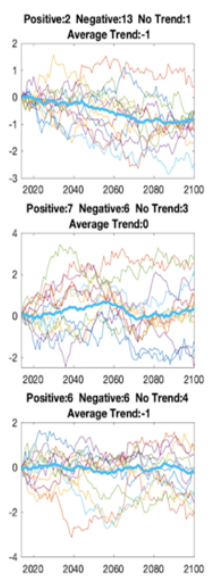

Figure 8. SON LSMP frequency trends. a. Colors indicate the number of models agreeing on statistically significance increase in frequency (orange), decrease in frequency (blue), or no change in frequency (gray). Numbers indicate historical MMEM LSMP frequency, defined by percentage of days over a 30 year time period assigned to that node. $\mathbf{b}$. Time series of individual model frequency per node. MMEM in blue. Average trend numbers indicate whether the MMEM trend shows significant increase (1) decrease (-1) or no change (0).

LSMP frequency changes for SON can be seen in figure 8. Models agree on significant increases in node 6 and node 7 , while agreeing on decreases in node 1, node 4 , node 5 , and node 10 . The nodes showing agreement on decrease are high amplitude anomaly patterns, with nearly all models agreeing on significant decrease for node 4 , a deep negative anomaly over the intermountain west and positive anomaly over the north Pacific. Notably, node 6 and node 7 are both relatively frequent patterns historically, with weak anomalies and weak height gradients, and show model agreement on an increase in frequency. This result is similar to results shown for JJA in figure 6, in which the common historical patterns that exhibited weak anomalies were found to have a high level of model agreement on significant increases by end of century. Node 2, node 9, and node 11 show model agreement on no change in frequency. 


\subsection{Internal Variability}

For the purposes of focusing on significant results, this analysis is confined to JJA and SON since MAM and DJF did not exhibit significant physical changes in the LSMP patterns.

a.

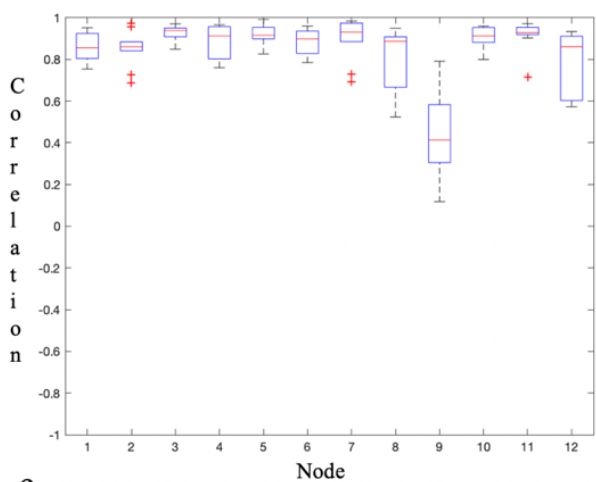

c.

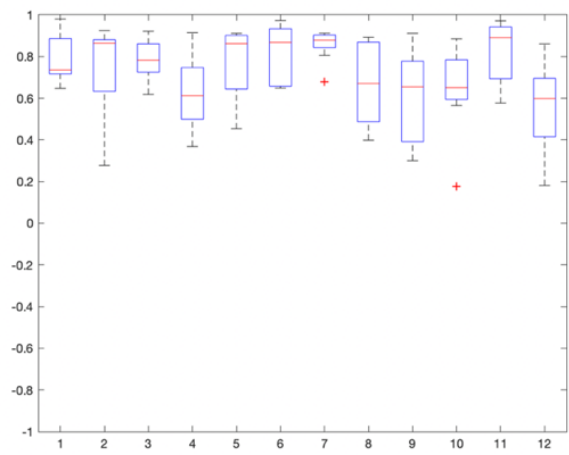

b.

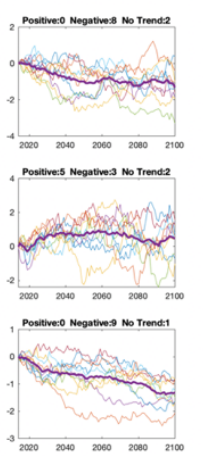

d.
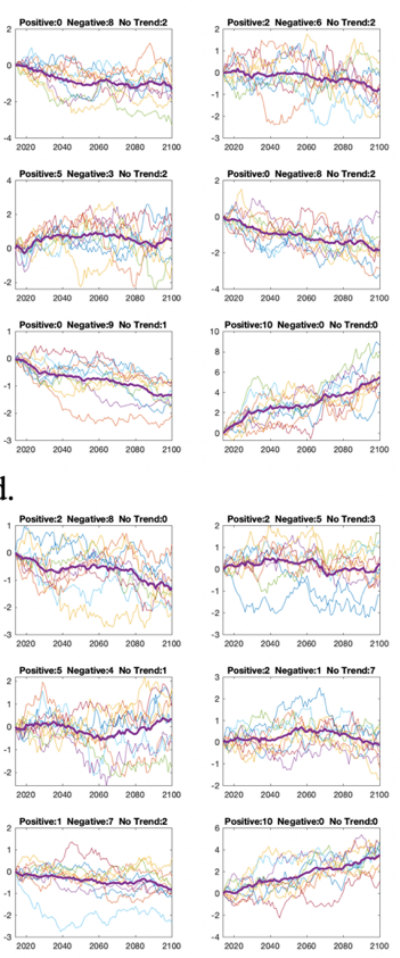
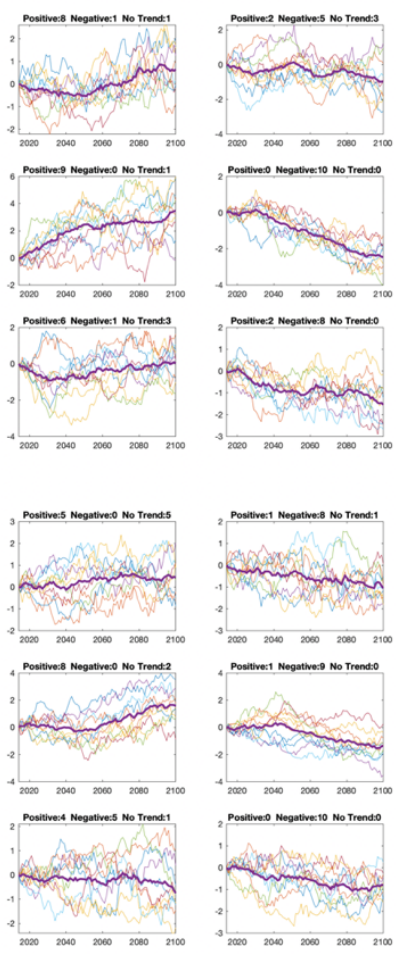

Figure 9. JJA internal variability results for change in anomalies and node frequency. a. Individual variant end of century change in Z500 anomaly results correlated with ensemble average, by node, for CanESM5. b. Time series of individual variant node frequency change, with variant ensemble average in purple, for CanESM5. c. As in panel a, for MPI-ESM1-2-LR. d. As in panel b, for MPI-ESM1-2-LR.

Figure 9 displays internal variability results for JJA. Box plots show the correlation of 10 initial condition variants with the ensemble mean end of century change in Z500 anomalies, for each node, for CanESM5 (figure 9a) and MPI-ESM1-2-LR in (figure 9c). Variants in both models generally show a high level of positive correlation 
with ensemble mean results across nodes, with higher variability in results in MPIESM1-2-LR. These results are interpreted together with figure $5 \mathrm{~b}$. Because of the strong agreement across variants on end of century change in Z500 anomalies, we are able to have more confidence that the significant changes in anomaly strength shown in figure $5 \mathrm{~b}$ are not due solely to internal variability of models.

Figure $9 \mathrm{~b}$ and $9 \mathrm{~d}$ show internal variability results for JJA LSMP frequency change for CanESM5 and MPI-ESM1-2-HR, respectively. Many nodes exhibit a high level of agreement among variants on the direction and significance of change in frequency, which align with model results displayed in Figure 6. Notably, variants strongly agree on significant decrease in frequency of node 8 , node 9 , and node 12 in both models tested. Variants also agree on significant increase in frequency of node 7 and node 10 . Because of this strong agreement across variants, we are able to have more confidence that changes in LSMP frequency displayed in Figure 6 are not due to internal variability of models, lending confidence that the results shown can be attributed to anthropogenic forcing, in the nodes that display a high level of agreement across variants. 


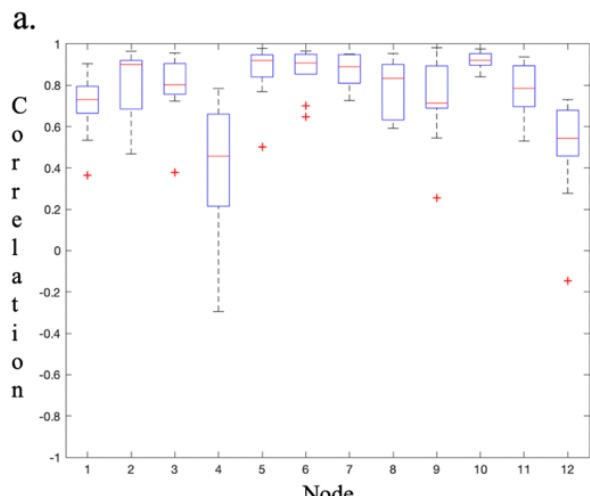

c.

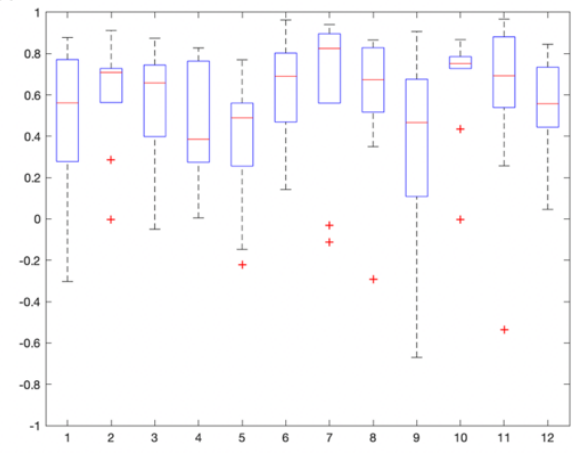

b.

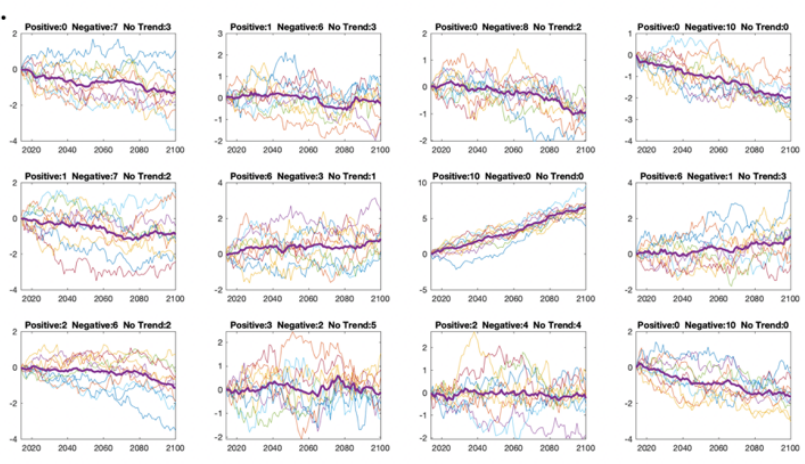

d.
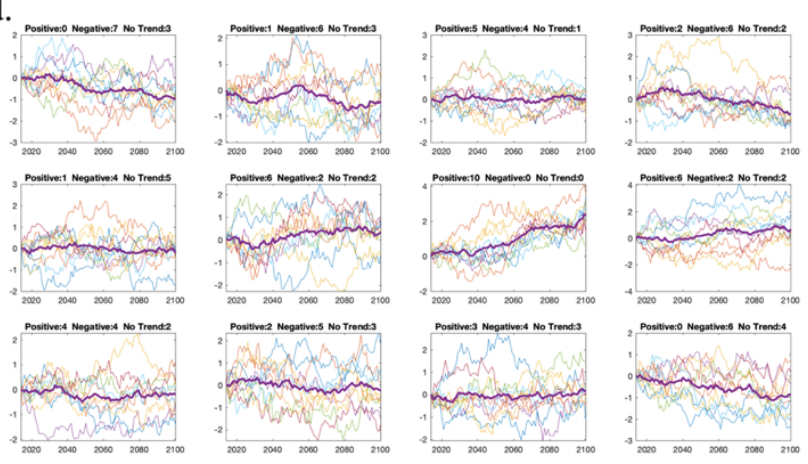

Figure 10. SON internal variability results for change in anomalies and node frequency. a. Individual variant end of century change in Z500 anomaly results correlated with ensemble average, by node, for CanESM5. b. Time series of individual variant node frequency change, with variant ensemble average in purple, for CanESM5. c. As in panel a, for MPI-ESM1-2-LR. d. As in panel b, for MPI-ESM1-2-LR.

Figure 9 displays internal variability results for SON. Box plots show the correlation of 10 initial condition variants with the ensemble mean end of century change in Z500 anomalies, for each node, for CanESM5 (figure 10a) and MPI-ESM1-2-LR in (figure 10c). Variants in CanESM5 results show a high level of correlation with ensemble mean results across nodes, with the exception of node 4 , which notably was not found to have significant change in the multi-model ensemble results (figure 7b). Figure 10c exhibits higher variability between variants. Because of the strong agreement across variants on end of century change in Z500 anomalies, we are able to have more confidence that the significant changes in anomaly strength shown in figure $7 \mathrm{~b}$ are not entirely due to internal variability of models, and that the results shown can be attributed 
to anthropogenic forcing. However, a degree of variability between different initial conditions is observed, lending more caution to conclusions about the primary signal influencing results.

Figure $10 \mathrm{~b}$ and $10 \mathrm{~d}$ show internal variability results for SON LSMP frequency change for CanESM5 and MPI-ESM1-2-HR, respectively. Many nodes exhibit a high level of agreement among variants on the direction and significance of change in frequency, which align with model results displayed in Figure 8. Variants agree on significant decrease in frequency of node 1 and node 4 in both models tested. Variants also agree on significant increase in frequency of node 6 and node 7, although with more of a spread in trend in node 6 . The universal agreement across variants and models on significant increase of node 7 matches the majority model agreement on significant increase of node 7 displayed in Figure 8. Because of this strong agreement across variants, we are able to have more confidence that changes in LSMP frequency displayed in Figure 8 are not due solely to internal variability of models, and that the results shown may be more confidently attributed to anthropogenic forcing, in the nodes that display a high level of agreement across variants.

The variable results between CanESM5 and MPI-ESM1-2-HR suggests that model internal variability has some level of influence on initial results, but the strong agreement on anomaly change and node frequency change in many LSMPs lends confidence to the conclusion that those results are due to anthropogenic forcing. 


\section{Conclusions}

This research attempts to use a novel method for evaluating climate model projections of atmospheric circulation patterns in the Pacific Northwest, and the associated changes in temperature and precipitation. Historical $500 \mathrm{hPa}$ geopotential height (Z500) anomalies are clustered into a range of 12 representative patterns for each meteorological season using the self-organizing maps method. In order to understand projected changes to the range and magnitude of synoptic circulation patterns over the region by the end of the $21^{\text {st }}$ century, Z500 anomaly data from climate model projections are mapped to historical reference patterns and evaluated for change in structure and frequency. Additionally, the projected temperature and precipitation associated with each pattern is evaluated for change. By analyzing these three variables, we create a robust assessment of how global warming may influence the structure, frequency, and associated temperature and precipitation of atmospheric circulation patterns.

The key conclusions can be summarized as follows:

- Models project a reduction in the amplitude of Z500 anomalies, with majority model agreement on significant reduction found in JJA and SON.

- A high level of warming is observed in all seasons, but with considerable spatial heterogeneity. In DJF, patterns historically associated with anomalous cold are observed to warm the most, whereas in JJA patterns historically associated with anomalous heat exhibit the highest level of warming. 
- Increases in precipitation are generally observed across seasons, with a concentration of significant results in increased precipitation in coastal areas north of Oregon. Patterns historically associated with JJA rainfall in the Pacific Northwest are observed to become up to $50 \%$ drier as a percentage,

- The frequency at which high amplitude Z500 anomaly patterns occur is found to generally decrease, with especially notable increases in weak amplitude patterns in JJA and SON.

- An analysis of internal model variability suggests that anomaly reduction and LSMP frequency change results in JJA and SON are not due to internal variability, and can thus be attributed to an anthropogenic climate change signal with more confidence.

Findings show that climate models project a decrease in amplitude of Z500 anomaly patterns over the region, although majority model agreement on significance is confined to JJA (figure 5b) and SON (figure 7b). JJA results exhibit a systematic reduction in the amplitude of Z500 anomalies, with positive anomalies decreasing in height and negative anomalies increasing in height. The majority of models agree on the significance and sign of change of these results in a considerable number of grid cells and nodes for JJA. Results for SON exhibit a similar pattern of reduction in anomalies, but the areas in which the majority of models agree on significance and sign of change is less than JJA.

Results show an increase of temperature in every season, for every pattern, but the magnitude of the temperature increase varies by pattern and season and is spatially heterogenous. In DJF, patterns historically associated with anomalously cold weather 
exhibit the highest levels of warming, as displayed in nodes 1-4 in Figure 1c, especially in areas more removed from the influence of the Pacific. In MAM, the highest levels are warming are observed over western British Columbia. In SON, the highest levels of warming are observed in the intermountain west and northern British Columbia. Patterns associated with anomalously warm weather in JJA are shown to exhibit the highest level of warming, as shown in nodes 10-12 in Figure 5c.

Precipitation is found to generally increase across the region in DJF, MAM, and SON, but majority model agreement suggests that the most robust results are confined to an increase in precipitation in western British Columbia. While multi-model ensemble mean projections for precipitation exhibited drying in MAM and SON in California and wetting in California in SON, models did not agree on changes to precipitation over California, apart from node 12 in figure $5 \mathrm{~d}$, which shows a considerable increase in precipitation as a percentage over the northern part of the state. Patterns that historically brought cool and wet weather to the Pacific Northwest in JJA are projected to become significantly drier and warmer, as shown by node 3 and node 4 in figure $5 \mathrm{c}$ and $5 \mathrm{~d}$.

In addition to analyzing changes in Z500 anomaly magnitude, the frequency of occurrence of LSMPs is evaluated by constructing a time series of LSMP frequency for each successive time period between 1985-2100 (1985-2014, 1986-2015, and so on), and analyzing the linear trend of LSMP frequency. Generally, results show a reduction in the frequency of high amplitude patterns and an increase in the frequency of weak patterns, although this is not a universal result. The reduction in frequency of high amplitude anomaly patterns was most apparent in JJA results (figure 6) and SON (figure 8). JJA results showed majority model agreement on significant increases in weak anomaly 
patterns that historically have constituted $30 \%$ of pattern occurrences, and model agreement on significant decreases in historically rare high amplitude anomaly patterns. Similarly, SON results showed an increase in patterns with weak anomalies and height gradients, and significant agreement on a decrease in patterns with strong anomalies and high amplitude trough and ridge patterns.

Results for JJA and SON were tested for internal model variability by repeating the analysis with 10 initial condition variants across two models (CanESM5, MPI-ESM12-LR), and analyzing individual variant results compared to variant ensemble results, in order to identify the degree to which internal variability affects future projections of circulation patterns versus external forcing. JJA results show a high level of correlation (figure 9a, 9c), with more variability shown in MPI-ESM1-2-LR, lending confidence to the decrease in anomaly amplitudes exhibited by models shown in figure $5 \mathrm{~b}$. Variants also agree on significant frequency changes in LSMPs (figure 9b, 9d). Likewise, SON variant results generally show a high level of correlation with average results, although with more variance than JJA results (figure 10a, 10c). SON internal variability results for SON (figure 10b, 10d) also show agreement on notable changes in LSMP frequencies.

This research attempts to provide a systematic analysis of the behavior of large scale circulation patterns of the Pacific Northwest under high end emissions scenarios of global warming. The approach outlined here lays the groundwork for similar work in other regions of North America, and the possibility of including additional variables in the analysis, contributing to knowledge of regional scale effects of global warming. 


\section{References}

Abatzoglou, J. T., Rupp, D. E., \& Mote, P. W. (2014). Seasonal Climate Variability and Change in the Pacific Northwest of the United States. Journal of Climate, 27(5), 2125-2142. https://doi.org/10.1175/JCLI-D-13-00218.1

Agel, L., Barlow, M., Colby, F., Binder, H., Catto, J. L., Hoell, A., \& Cohen, J. (2019). Dynamical analysis of extreme precipitation in the US northeast based on largescale meteorological patterns. Climate Dynamics, 52(3), 1739-1760. https://doi.org/10.1007/s00382-018-4223-2

Aragon, C. M., Loikith, P. C., McCullar, N., \& Mandilag, A. (2020). Connecting localscale heavy precipitation to large-scale meteorological patterns over Portland, Oregon. International Journal of Climatology, 40(11), 4763-4780. https://doi.org/10.1002/joc.6487

Barnes, E. A. (2013). Revisiting the evidence linking Arctic amplification to extreme weather in midlatitudes. Geophysical Research Letters, 40(17), 4734-4739. https://doi.org/10.1002/grl.50880

Belleflamme, A., Fettweis, X., Lang, C., \& Erpicum, M. (2013). Current and future atmospheric circulation at $500 \mathrm{hPa}$ over Greenland simulated by the CMIP3 and CMIP5 global models. Climate Dynamics; Heidelberg, 41(7-8), 2061-2080. http://dx.doi.org.proxy.lib.pdx.edu/10.1007/s00382-012-1538-2

Brewer, M. C., \& Mass, C. F. (2016). Projected Changes in Western U.S. Large-Scale Summer Synoptic Circulations and Variability in CMIP5 Models. Journal of Climate, 29(16), 5965-5978. https://doi.org/10.1175/JCLI-D-15-0598.1

Cassano, E. N., Glisan, J. M., Cassano, J. J., Jr, W. J. G., \& Seefeldt, M. W. (2015). Selforganizing map analysis of widespread temperature extremes in Alaska and Canada. Climate Research, 62(3), 199-218. https://doi.org/10.3354/cr01274

-------, J. J., Uotila, P., \& Lynch, A. (2006). Changes in synoptic weather patterns in the polar regions in the twentieth and twenty-first centuries, part 1: Arctic. International Journal of Climatology, 26(8), 1027-1049. https://doi.org/10.1002/joc.1306

Cavazos, T. (2000). Using Self-Organizing Maps to Investigate Extreme Climate Events: An Application to Wintertime Precipitation in the Balkans. Journal of Climate, 13(10), 1718-1732. https://doi.org/10.1175/15200442(2000)013<1718:USOMTI $>2.0 . \mathrm{CO} ; 2$ 
Cohen, J., Screen, J. A., Furtado, J. C., Barlow, M., Whittleston, D., Coumou, D., Francis, J., Dethloff, K., Entekhabi, D., Overland, J., \& Jones, J. (2014). Recent Arctic amplification and extreme mid-latitude weather. Nature Geoscience, 7(9), 627-637. https://doi.org/10.1038/ngeo2234

Collow, A. B. M., Bosilovich, M. G., \& Koster, R. D. (2016). Large-Scale Influences on Summertime Extreme Precipitation in the Northeastern United States. Journal of Hydrometeorology, 17(12), 3045-3061. https://doi.org/10.1175/JHM-D-160091.1

Davini, P., Cagnazzo, C., Gualdi, S., \& Navarra, A. (2012). Bidimensional Diagnostics, Variability, and Trends of Northern Hemisphere Blocking. Journal of Climate, 25(19), 6496-6509. https://doi.org/10.1175/JCLI-D-12-00032.1

Dettinger, M. (2011). Climate Change, Atmospheric Rivers, and Floods in California - A Multimodel Analysis of Storm Frequency and Magnitude Changes1. JAWRA Journal of the American Water Resources Association, 47(3), 514-523. https://doi.org/10.1111/j.1752-1688.2011.00546.x

Eyring, V., Bony, S., Meehl, G. A., Senior, C. A., Stevens, B., Stouffer, R. J., \& Taylor, K. E. (2016). Overview of the Coupled Model Intercomparison Project Phase 6 (CMIP6) experimental design and organization. Geoscientific Model Development, 9(5), 1937-1958. https://doi.org/10.5194/gmd-9-1937-2016

Ford, T. W., \& Schoof, J. T. (2017). Characterizing extreme and oppressive heat waves in Illinois. Journal of Geophysical Research: Atmospheres, 122(2), 682-698. https://doi.org/10.1002/2016JD025721

Francis, J. A., \& Vavrus, S. J. (2012). Evidence linking Arctic amplification to extreme weather in mid-latitudes. Geophysical Research Letters, 39(6). https://doi.org/10.1029/2012GL051000

Gao, X., Schlosser, C. A., Xie, P., Monier, E., \& Entekhabi, D. (2014). An Analogue Approach to Identify Heavy Precipitation Events: Evaluation and Application to CMIP5 Climate Models in the United States. Journal of Climate, 27(15), 59415963. https://doi.org/10.1175/JCLI-D-13-00598.1

Gao, Y., Lu, J., Leung, L. R., Yang, Q., Hagos, S., \& Qian, Y. (2015). Dynamical and thermodynamical modulations on future changes of landfalling atmospheric rivers over western North America. Geophysical Research Letters, 42(17), 7179-7186. https://doi.org/10.1002/2015GL065435

Gelaro, R., McCarty, W., Suárez, M. J., Todling, R., Molod, A., Takacs, L., Randles, C. A., Darmenov, A., Bosilovich, M. G., Reichle, R., Wargan, K., Coy, L., Cullather, R., Draper, C., Akella, S., Buchard, V., Conaty, A., da Silva, A. M., Gu, W., ... 
Zhao, B. (2017). The Modern-Era Retrospective Analysis for Research and Applications, Version 2 (MERRA-2). Journal of Climate, 30(14), 5419-5454. https://doi.org/10.1175/JCLI-D-16-0758.1

Gibson, P. B., Perkins-Kirkpatrick, S. E., \& Renwick, J. A. (2016). Projected changes in synoptic weather patterns over New Zealand examined through self-organizing maps. International Journal of Climatology, 36(12), 3934-3948. https://doi.org/10.1002/joc.4604

--------, Pitman, A. J., Lorenz, R., \& Perkins-Kirkpatrick, S. E. (2017). The Role of Circulation and Land Surface Conditions in Current and Future Australian Heat Waves. Journal of Climate, 30(24), 9933-9948. https://doi.org/10.1175/JCLI-D17-0265.1

Glisan, J. M., Gutowski, W. J., Cassano, J. J., Cassano, E. N., \& Seefeldt, M. W. (2016). Analysis of WRF extreme daily precipitation over Alaska using self-organizing maps. Journal of Geophysical Research: Atmospheres, 121(13), 7746-7761. https://doi.org/10.1002/2016JD024822

Grotjahn, R. (2013). Ability of CCSM4 to simulate California extreme heat conditions from evaluating simulations of the associated large scale upper air pattern. Climate Dynamics, 41(5), 1187-1197. https://doi.org/10.1007/s00382-013-1668-1

-------, Black, R., Leung, R., Wehner, M. F., Barlow, M., Bosilovich, M., Gershunov, A., Gutowski, W. J., Gyakum, J. R., Katz, R. W., Lee, Y.-Y., Lim, Y.-K., \& Prabhat. (2016). North American extreme temperature events and related large scale meteorological patterns: a review of statistical methods, dynamics, modeling, and trends. Climate Dynamics, 46(3), 1151-1184. https://doi.org/10.1007/s00382015-2638-6

--------, \& Faure, G. (2008). Composite Predictor Maps of Extraordinary Weather Events in the Sacramento, California, Region. Weather and Forecasting, 23(3), 313-335. https://doi.org/10.1175/2007WAF2006055.1

Hagos, S. M., Leung, L. R., Yoon, J.-H., Lu, J., \& Gao, Y. (2016). A projection of changes in landfalling atmospheric river frequency and extreme precipitation over western North America from the Large Ensemble CESM simulations. Geophysical Research Letters, 43(3), 1357-1363. https://doi.org/10.1002/2015GL067392

Hewitson, B. C., \& Crane, R. G. (2002). Self-organizing maps: applications to synoptic climatology. Climate Research, 22(1), 13-26. https://doi.org/10.3354/cr022013

Horton, D. E., Johnson, N. C., Singh, D., Swain, D. L., Rajaratnam, B., \& Diffenbaugh, N. S. (2015). Contribution of changes in atmospheric circulation patterns to 
extreme temperature trends. Nature, 522(7557), 465-469.

https://doi.org/10.1038/nature14550

Horton, R. M., Mankin, J. S., Lesk, C., Coffel, E., \& Raymond, C. (2016). A Review of Recent Advances in Research on Extreme Heat Events. Current Climate Change Reports, 2(4), 242-259. https://doi.org/10.1007/s40641-016-0042-x

Huang, X., \& Ullrich, P. A. (2017). The Changing Character of Twenty-First-Century Precipitation over the Western United States in the Variable-Resolution CESM. Journal of Climate, 30(18), 7555-7575. https://doi.org/10.1175/JCLI-D-160673.1

Johnson, N. C., \& Feldstein, S. B. (2010). The Continuum of North Pacific Sea Level Pressure Patterns: Intraseasonal, Interannual, and Interdecadal Variability. Journal of Climate, 23(4), 851-867. https://doi.org/10.1175/2009JCLI3099.1

-------, -------, \& Tremblay, B. (2008). The Continuum of Northern Hemisphere Teleconnection Patterns and a Description of the NAO Shift with the Use of SelfOrganizing Maps. Journal of Climate, 21(23), 6354-6371. https://doi.org/10.1175/2008JCLI2380.1

Lackmann, G. M., \& Gyakum, J. R. (1999). Heavy Cold-Season Precipitation in the Northwestern United States: Synoptic Climatology and an Analysis of the Flood of 17-18 January 1986. Weather and Forecasting, 14(5), 687-700. https://doi.org/10.1175/1520-0434(1999)014<0687:HCSPIT>2.0.CO;2

Lennard, C., \& Hegerl, G. (2015). Relating changes in synoptic circulation to the surface rainfall response using self-organising maps. Climate Dynamics, 44(3), 861-879. https://doi.org/10.1007/s00382-014-2169-6

Liu, P., Zhu, Y., Zhang, Q., Gottschalck, J., Zhang, M., Melhauser, C., Li, W., Guan, H., Zhou, X., Hou, D., Peña, M., Wu, G., Liu, Y., Zhou, L., He, B., Hu, W., \& Sukhdeo, R. (2018). Climatology of tracked persistent maxima of 500-hPa geopotential height. Climate Dynamics, 51(1), 701-717. https://doi.org/10.1007/s00382-017-3950-0

Loikith, P. C., \& Broccoli, A. J. (2012). Characteristics of Observed Atmospheric Circulation Patterns Associated with Temperature Extremes over North America. Journal of Climate, 25(20), 7266-7281. https://doi.org/10.1175/JCLI-D-1100709.1

\& ------ (2015). Comparison between Observed and Model-Simulated Atmospheric Circulation Patterns Associated with Extreme Temperature Days over North America Using CMIP5 Historical Simulations. Journal of Climate, 28(5), 2063-2079. https://doi.org/10.1175/JCLI-D-13-00544.1 
-------, Lintner, B. R., \& Sweeney, A. (2017). Characterizing Large-Scale Meteorological Patterns and Associated Temperature and Precipitation Extremes over the Northwestern United States Using Self-Organizing Maps. Journal of Climate, 30(8), 2829-2847. https://doi.org/10.1175/JCLI-D-16-0670.1

Mahoney, K., Swales, D., Mueller, M. J., Alexander, M., Hughes, M., \& Malloy, K. (2018). An Examination of an Inland-Penetrating Atmospheric River Flood Event under Potential Future Thermodynamic Conditions. Journal of Climate, 31(16), 6281-6297. https://doi.org/10.1175/JCLI-D-18-0118.1

Mechem, D. B., Wittman, C. S., Miller, M. A., Yuter, S. E., \& Szoeke, S. P. de. (2018). Joint Synoptic and Cloud Variability over the Northeast Atlantic near the Azores. Journal of Applied Meteorology and Climatology, 57(6), 1273-1290. https://doi.org/10.1175/JAMC-D-17-0211.1

Meehl, G. A., \& Tebaldi, C. (2004). More Intense, More Frequent, and Longer Lasting Heat Waves in the 21st Century. Science, 305(5686), 994-997. https://doi.org/10.1126/science.1098704

Mote, P. W., \& Salathé, E. P. (2010). Future climate in the Pacific Northwest. Climatic Change, 102(1), 29-50. https://doi.org/10.1007/s10584-010-9848-z

Radić, V., Cannon, A. J., Menounos, B., \& Gi, N. (2015). Future changes in autumn atmospheric river events in British Columbia, Canada, as projected by CMIP5 global climate models. Journal of Geophysical Research: Atmospheres, 120(18), 9279-9302. https://doi.org/10.1002/2015JD023279

Rana, A., \& Moradkhani, H. (2016). Spatial, temporal and frequency based climate change assessment in Columbia River Basin using multi downscaled-scenarios. Climate Dynamics, 47(1), 579-600. https://doi.org/10.1007/s00382-015-2857-x

Röthlisberger, M., Pfahl, S., \& Martius, O. (2016). Regional-scale jet waviness modulates the occurrence of midlatitude weather extremes. Geophysical Research Letters, 43(20), 10,989-10,997. https://doi.org/10.1002/2016GL070944

Rupp, D. E., Abatzoglou, J. T., \& Mote, P. W. (2017). Projections of 21st century climate of the Columbia River Basin. Climate Dynamics, 49(5), 1783-1799. https://doi.org/10.1007/s00382-016-3418-7

Salathé, E. P. (2006). Influences of a shift in North Pacific storm tracks on western North American precipitation under global warming. Geophysical Research Letters, 33(19). https://doi.org/10.1029/2006GL026882 
Schlef, K. E., Moradkhani, H., \& Lall, U. (2019). Atmospheric Circulation Patterns Associated with Extreme United States Floods Identified via Machine Learning. Scientific Reports, 9(1), 7171. https://doi.org/10.1038/s41598-019-43496-w

Screen, J. A. (2014). Arctic amplification decreases temperature variance in northern mid- to high-latitudes. Nature Climate Change, 4(7), 577-582. https://doi.org/10.1038/nclimate2268

\& Simmonds, I. (2013). Exploring links between Arctic amplification and midlatitude weather. Geophysical Research Letters, 40(5), 959-964. https://doi.org/10.1002/grl.50174

(2014). Amplified mid-latitude planetary waves favour particular regional weather extremes. Nature Climate Change, 4(8), 704-709. https://doi.org/10.1038/nclimate2271

Sinha, P., Mann, M. E., Fuentes, J. D., Mejia, A., Ning, L., Sun, W., He, T., \& Obeysekera, J. (2018). Downscaled rainfall projections in south Florida using self-organizing maps. Science of The Total Environment, 635, 1110-1123. https://doi.org/10.1016/j.scitotenv.2018.04.144

Teng, H., \& Branstator, G. (2017). Causes of Extreme Ridges That Induce California Droughts. Journal of Climate, 30(4), 1477-1492. https://doi.org/10.1175/JCLI-D16-0524.1

U.S. Global Change Research Program, Wuebbles, D. J., Fahey, D. W., Hibbard, K. A., Dokken, D. J., Stewart, B. C., \& Maycock, T. K. (2017). Climate Science Special Report: Fourth National Climate Assessment, Volume I. U.S. Global Change Research Program. https://doi.org/10.7930/J0J964J6

Warner, M. D., Mass, C. F., \& Salathé, E. P. (2012). Wintertime Extreme Precipitation Events along the Pacific Northwest Coast: Climatology and Synoptic Evolution. Monthly Weather Review, 140(7), 2021-2043. https://doi.org/10.1175/MWR-D11-00197.1 (2015). Changes in Winter Atmospheric Rivers along the North American West Coast in CMIP5 Climate Models. Journal of Hydrometeorology, 16(1), 118-128. https://doi.org/10.1175/JHM-D-14-0080.1 